

\section{DISCLAIMER}

Portions of this document may be illegible in electronic image products. Images are produced from the best available original document. 


\section{NOTICE}

This report was prepared as an account of work sponsored by the United States Government. Neither the United States nor the U.S. DOE, nor any of their employees, nor any of their contractors, subcontractors, or their employees, makes any warranty, express or implied, or assumes any legal liability or responsibility for the accuracy, completeness or usefulness of any information, apparatus, product or process disclosed, or represents that its use would not infringe privately owned rights.

Printed in the United States of America

Available from

National Technical Information Service

U.S. Department of Commerce

5285 Port Royal Road

Springfield, Virginia 22161

Price: Printed Copy $\$ 6.00$; Microfiche $\$ 2.25$ 


\section{NUCLEATION AND CAPTURE OF CONDENSIBLE AIRBORNE CONTAMINANTS IN AN AQUEOUS SCRUBBING SYSTEM}

\section{Hanford Engineering Development Laboratory}

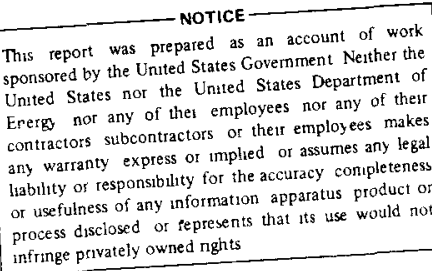

A. K. Postma*

R. K. Hilliard

September, 1978

"Consultant

HANFORD ENGINEERING DEVELOPMENT LABORATORY

Operated by Westinghouse Hanford Company

P.0. Box 1970 Richland, WA 99352

A Subsidiary of Westinghouse Electric Corporation

Prepared for the U.S. Department of Energy under Contract No. EY-76-C-142170 
-

-

$+$

• 


\title{
NUCLEATION AND CAPTURE OF CONDENSIBLE AIRBORNE CONTAMINANTS IN AN AQUEOUS SCRUBBING SYSTEM
}

\author{
A. K. Postma \\ R. K. Hilliard
}

\begin{abstract}
The fate of condensible contaminants in an aqueous scmibbing system was evaluated. Knowledge of the behavior of volatile fission product compounds is important in evaluating the effectiveness of emergency air cleaning systems proposed for use in containment systems of breeder reactor plants. When a high temperature air stream passes through a spray quench chamber, very large cooling rates occur in the drop boundary layers. These large cooling rates cause large supersaturations in airborme concentrations of condensible contaminants, and one predicts that most condensation would take place through homogeneous nucleation. The very small particles formed would agglomerate, and attach to sodium aerosol particles which would be present. In this study the overall removal efficiency of volatile fission product species (typified by $\mathrm{NaI}$, $\mathrm{SeO}_{2}$, and $\mathrm{Sb}_{2} \mathrm{O}_{3}$ ) in an air cleaning train (quench chamber, venturi scmibber, and fibrous bed) was theoretically evaluated.

The overall removal efficiency of condensible materials was found to be lower than that for sodium compound aerosols because the freshly condensed particles would be smaller in size. For a base case, a removal efficiency of $99.97 \%$ was predicted for condensible materials. The fibrous bed scmbber exhibited superior particle removal characteristics for small particles compared to the quench chamber and venturi scmubber. Its removal efficiency exceeded 97\% for even the most penetrating particle size (about 0.4 micron aerodynomic dicometer). Therefore, all condensible fission products would be removed with efficiencies exceeding $97 \%$.
\end{abstract}


- 


\section{CONTENTS}

Abstract $\quad$ i i i

Figures vij

Tables $\quad$ ix

I. EXECUTIVE SUMMARY 1

A. THE PROBLEM 1

B. APPROACH USED 1

C. CONCLUSIONS AND RECOMMENDATIONS 2

II. INTRODUCTION 3

III. OBJECTIVE OF THIS WORK

IV. BACKGROUND 4

A. CONTAINMENT SYSTEM DESIGN FOR SCRUBBER APPLICATION 4

B. AIR CLEANING SYSTEM CONCEPT STUDIED 6

C. VOLATILE FISSION PRODUCTS

D. GAS COOLING RATE IN A WATER SPRAY 8

V. APPROACH USED IN PRESENT STUDY 9

A. MODELING OF AEROSOL FORMATION AND REMOVAL 9

1. Nucleation 9

2. Agglomeration and Attachment 9

3. Particle Removal in Air Cleaning Components 9

$\begin{array}{ll}\text { B. PARAMETRIC ANALYSIS } & 10\end{array}$

VI. DESCRIPTION OF AIR CLEANING SYSTEM ANALYZED

A. OVERALL SCHEMATIC RELATIONSHIP OF EACS TO CONTAINMENT SYSTEM 


\section{CONTENTS (cont'd)}

Page

B. IMPORTANT EACS COMPONENTS

1. Quench Chamber

2. Venturi Scrubber

3. Fibrous Bed Scrubber

VII. NUCLEATION AND FORMATION OF FISSION PRODUCT AEROSOL

A. NUCLEATION FROM THE GAS PHASE

B. EQUATIONS FOR COMPUTING SUPERSATURATION IN A COOLING GAS 24

C. COOLING RATE EXPERIENCED IN SPRAY QUENCH CHAMBER

D. SIZE OF NUCLEATED PARTICLES

VIII. ATTACHMENT OF NUCLEI TO SODIUM AEROSOL

A. MODEL FOR ATTACHMENT PROCESS

B. ASSESSMENT OF APPROXIMATIONS IN MODEL 37

IX. AEROSOL CAPTURE IN SCRUBBER COMPONENTS 38

A. QUENCH SPRAY CHAMBER 38

1. Modeling Approach 38

2. Collection Mechanisms 39

B. EDUCTOR VENTURI 41

1. Modeling Approach 41

2. Design Parameter Values 41

C. FIBROUS BED SCRUBBER 42

1. Modeling Approach 42

2. Aerosol Capture Mechanisms 43

3. Penetration/Size Curve 44 


\section{CONTENTS (cont'd)}

$\underline{\text { Page }}$

X. PARAMETRIC EVALUATIONS

A. VARIABLES CONSIDERED 46

1. Properties of Volatile Material 46

2. Properties of Sodium Aerosol 50

3. Thermal Conditions in Quench Chamber 52

4. Time for Attachment of Nuclei to Sodium Aerosol 54

5. Removal Efficiency of Scrubber Components 54

B. AEROSOL REMOVAL PREDICTED FOR BASE CASE 56

1. Homogeneous Nucleation vs. Heterogeneous Nucleation 56

2. Sizes of Aerosol Particles 56

3. Fraction of $\mathrm{NaI}$ Aerosol Attached to Sodium Aerosol 58

4. Aerosol Removal in Scrubber 58

C. RESULTS OF PARAMETRIC ANALYSIS 59

1. Effect of Gas Flow Rate 59

2. Effect of Sodium Aerosol Concentration 59

3. Effect of Spray Fall Height in Quench Chamber 61

4. Effect of Thickness of Fibrous Bed Scrubber 63

5. Effect of Fiber Diameter in Fibrous Bed Scrubber 63

6. Effect of Mass Concentration of Condensible Vapor 66

XI. SUMMARY AND CONCLUSIONS

$\begin{array}{lll}\text { XII. REFERENCES } & 73\end{array}$ 


\section{FIGURES}

Page

1. Schematic Diagram of Reactor Containment Employing Scrubber EACS

2. Schematic Diagram of Scrubber System Analyzed 6

3. Schematic Diagram of EACS Application to Containment System 11

4. Quench Chamber

5. Eductor Venturi Scrubber 14

6. Fibrous Bed Scrubber 15

7. Free Energy Change for Drop Growth ${ }^{(4)} 17$

8. Nucleation Rate for Water Vapor as a Function of the Saturation Ratio

9. Nucleation In the Presence of an Insoluble Surface

10. Critical Saturation Ratio for $\mathrm{J}=1 \mathrm{~cm}^{-2} \mathrm{sec}^{-1}$ Upon a Plane Substrate of Given Contact Angle, at $0^{\circ} \mathrm{C}$

11. Critical Saturation Ratio for Nucleation of a Water Droplet in One Second Upon a Particle of Given Radius and with

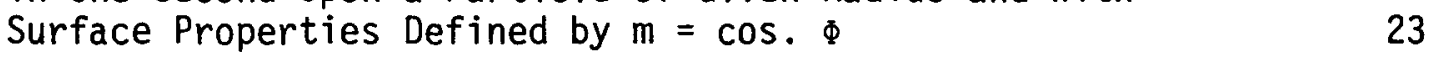

12. Cooling and Supersaturation of a Gas Parcel 25

13. Supersaturation Achieved When $\mathrm{NaI}$ is Cooled in the Presence of Sodium Aerosol

14. Boundary Layer Around Falling Drop 31

15. Particle Penetration Through Fiber Bed 45

16. Vapor Pressure of Sodium Iodide 48

17. Correlation of Particle Size With Aerosol Concentration in Containment Atmosphere

18. Size of Particles Populations for Base Case 57 


\section{FIGURES (cont'd)}

$\underline{\text { Page }}$

19. Effect of Gas Flow Rate on the Penetration of Aerosols Through Scrubbing System

20. Effect of Sodium Aerosol Concentration on Penetration of Aerosols Through Scrubbing System

21. Effect of Quench Spray Fal1 Height on Aerosol Penetration

22. Effect of Thickness of Fibrous Bed Scrubber on Aerosol Penetration

23. Effect of Fiber Diameter in Fibrous Bed Scrubber on Aerosol Penetration

24. Effect of Volatile Mass on Aerosol Penetration

\section{TABLES}

1. Aerosol Penetration Through Scrubber Components for The Base Case

2. Core Inventories of Potentially Volatile Elements

3. Temperature Required to Vaporize Core Inventory of Fission Products airborne as $\mathrm{NaI}, \mathrm{Sb}_{2} \mathrm{O}_{3}$, and $\mathrm{SeO}_{2}$ 


\section{EXECUTIVE SUMMARY}

\section{A. THE PROBLEM}

An air cleaning system may be useful in reducing the risk of low probability accidents in fast breeder reactor plants. Such a system would remove sodium combustion products and radioactive materials from gases vented from the containment vessel. Venting would occur only under accident conditions where emergency core cooling was ineffectual.

It has been postulated that several fission product species undergo a gas-to-solid transition in an aqueous scrubber. Fission product species, such as $\mathrm{NaI}, \mathrm{SeO}_{2}$, and $\mathrm{Sb}_{2} \mathrm{O}_{3}$, are airborne as gases in the containment atmosphere (temperature to $538^{\circ} \mathrm{C}\left[1000^{\circ} \mathrm{F}\right]$ ) but are solids in cooled exhaust gas (temperature to $38^{\circ} \mathrm{C}\left[100^{\circ} \mathrm{F}\right]$ ).

When the contaminated airstream is cooled in an aqueous spray quench chamber, the condensible materials nucleate to form a verv fine aerosol, or condense on sodium compound aerosol particles, also present.

The technical problem evaluated here may be stated: "What is the removal efficiency of condensible fission product species in the air cleaning system?"

\section{B. APPROACH USED}

The technical problem was attacked by developing mathematical models which would serve to predict the nucleation, attachment to sodium aerosol particles, and removal of condensible fission product compounds in the air cleaning system. Selected variables were treated as parameters in this study. The scrubber removal efficiency was computed for a range of values of each parameter surrounding a baseline value. 


\section{CONCLUSIONS AND RECOMMENDATIONS}

It was concluded that condensible fission products undergo homogeneous nucleation in the quench spray, and form very fine aerosol particles. These particles agglomerate, and by diffusion become attached to sodium aerosol particles. While the overall removal efficiency of the condensible materials was found to be lower than that for sodium compound aerosols (because the freshly condensed particles are smaller) comparatively high removal efficiencies are obtainable. For example, an efficiency of $99.97 \%$ was predicted for condensible materials in the base case.

The Emergency Air Cleaning System (EACS) consists of a quench chamber, venturi scrubber, and a fibrous bed scrubber. The fibrous bed scrubber exhibited superior particle removal characteristics for small particles compared to the quench chamber and venturi scrubber. Its removal efficiency exceeded $97 \%$ for even the most penetrating particle size (about 0.4 micron aerodynamic diameter). Therefore, all condensible fission products would be removed with efficiencies exceeding $97 \%$.

The minimum removal efficiency can be confirmed experimentally by testing the scrubber with an aerosol having a mass median aerodynamic diameter of approximately 0.4 micron. While the present study shows that condensible fission products are removed with an efficiency appreciably higher than the minimum value, additional work needs to be done to confirm the predicted higher efficiencies. 


\section{INTRODUCTION}

This report presents the results of a theoretical evaluation to determine how efficiently volatile fission product compounds would be captured in a scrubber. Volatile fission product compounds are defined as those whose vapor pressures are high enough so they are gases in the containment atmosphere, but low enough so that they are solids or liquids in scrubber exhaust gas.

An Emergency Air Cleaning System (EACS) will trap radioactive materials carried with air vented from a reactor containment building. Containment venting occurs only under the circumstance of a low probability core disruptive accident. The accident risk associated with low probability accidents can be reduced by an order of magnitude through use of an EACS.

Air cleaning concepts were evaluated for application to LMFBR accident conditions in a previous study ${ }^{(1)}$. However, only particulate contaminants were considered in the previous study, so the behavior of volatile materials was not elucidated.

It has recently been postulated that several important fission products might exist as gases in the containment atmosphere. At the containment temperatures involved, (up to $538^{\circ} \mathrm{C}\left[1000^{\circ} \mathrm{F}\right]$ ) compounds such as $\mathrm{NaI}$, $\mathrm{SeO}_{2}$, and $\mathrm{Sb}_{2} \mathrm{O}_{3}$, would exist as vapors, if they were somehow released from the fuel and entered the containment atmosphere. In this report, the presence of volatile fission product compounds in the containment atmosphere is postulated in evaluating the performance of a scrubber system.

Very high cooling rates occur when the vented containment gases flow into a spray quench. Since the final temperatures would be lower than the saturation temperature for the volatile materials cited above, nucleation and condensation would occur. The effort in the present study centered 
on predicting the size of particles formed by the condensation process, and their capture in downstream scrubber components.

This study was carried out using present state-of-the-art knowledge of particle formation and capture. The approach adopted was to use the simplest tools available which would provide reasonable engineering estimates of the formation and capture processes involved.

\section{OBJECTIVE OF THIS WORK}

The objective of this study was to estimate the efficiency of a scrubber for removing volatile fission products.

\section{BACKGROUND}

\section{A. CONTAINMENT SYSTEM DESIGN FOR SCRUBBER APPLICATION}

The reference containment system design for the scrubber air cleaning system consisted of a pressure-withstanding inner she11, a gas annulus, an outer shell, a filter system to decontaminate leakage, and a separate EACS used to clean purge air in the event of a core disruptive accident more severe than the design base accident. This system is shown schematically in Figure 1 .

Under all credible accident conditions, the containment system is kept sealed and the only atmospheric discharge would be a small amount of leakage through the steel shell and shield structure. For all design basis accidents the pipes which exhaust air through the EACS remain sealed.

The purge air system reduces the risk from very low probability but high consequence core disruptive accidents. Purging of the containment atmosphere decreases the hydrogen concentration and thus eliminates the 
possibility of abrupt venting of contained gases due to containment overpressure.

In the accident scenarios which employ the scrubber EACS, purging of the containment atmosphere begins 24 hours or more after an unprotected core melt event had occurred. Gas flow rates are limited to a maximum of $9.44 \mathrm{std} \mathrm{m}^{3} / \mathrm{sec}(20,000 \mathrm{SCFM})$. The purge rate declines with time to about $0.47 \mathrm{std} \mathrm{m}^{3} / \mathrm{sec}(1000 \mathrm{SCFM})$ at 100 hours. Gas temperatures rise to a maximum of $538^{\circ} \mathrm{C}\left(1000^{\circ} \mathrm{F}\right)$ and then decline. A concentrated aerosol formed by oxidation of airborne sodium (oxides, carbonate, and hydroxide of sodium) are present in exhausted containment air. The very large aerosol mass carried from the containment building (up to $100,000 \mathrm{~kg}$ ) dictates the use of a scrubber as opposed to alternative dry collectors.

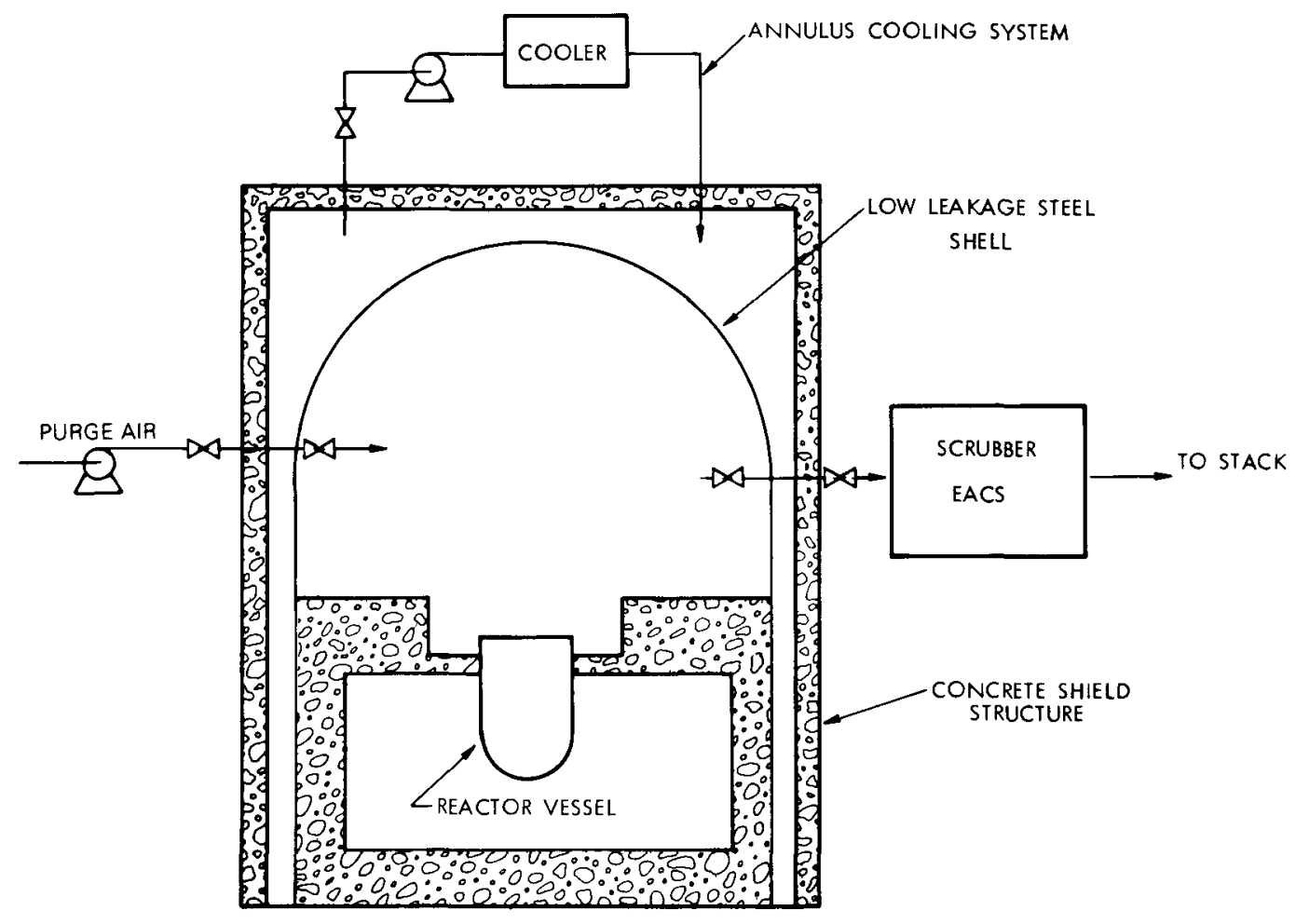

HEDL $7805-009.5$

FIGURE 1. Schematic Diagram of Reactor Containment Employing Scrubber EACS. 


\section{B. AIR CLEANING SYSTEM CONCEPT STUDIED}

The scrubber air cleaning system selected for study in the present application consists of: 1) a quench chamber, 2) a venturi scrubber, and 3) a fibrous bed scrubber. These three equipment items, operated in series, are pictured schematically in Figure 2. This system possesses the necessary properties to accommodate the following important characteristics of the purged containment gases:

- Inlet temperatures as high as $538^{\circ} \mathrm{C}\left(1000^{\circ} \mathrm{F}\right)$.

- Aerosol mass load of 100,000 kg (220,000 lb).

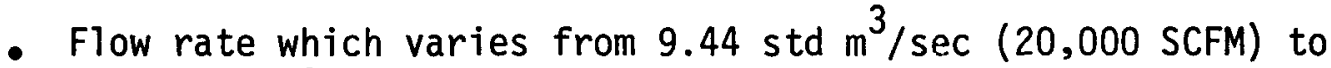
0.094 std $\mathrm{m}^{3} / \mathrm{sec}$ (200 SCFM).

- Particle size spectrum which includes submicron particles and particles larger than 20 microns diameter.

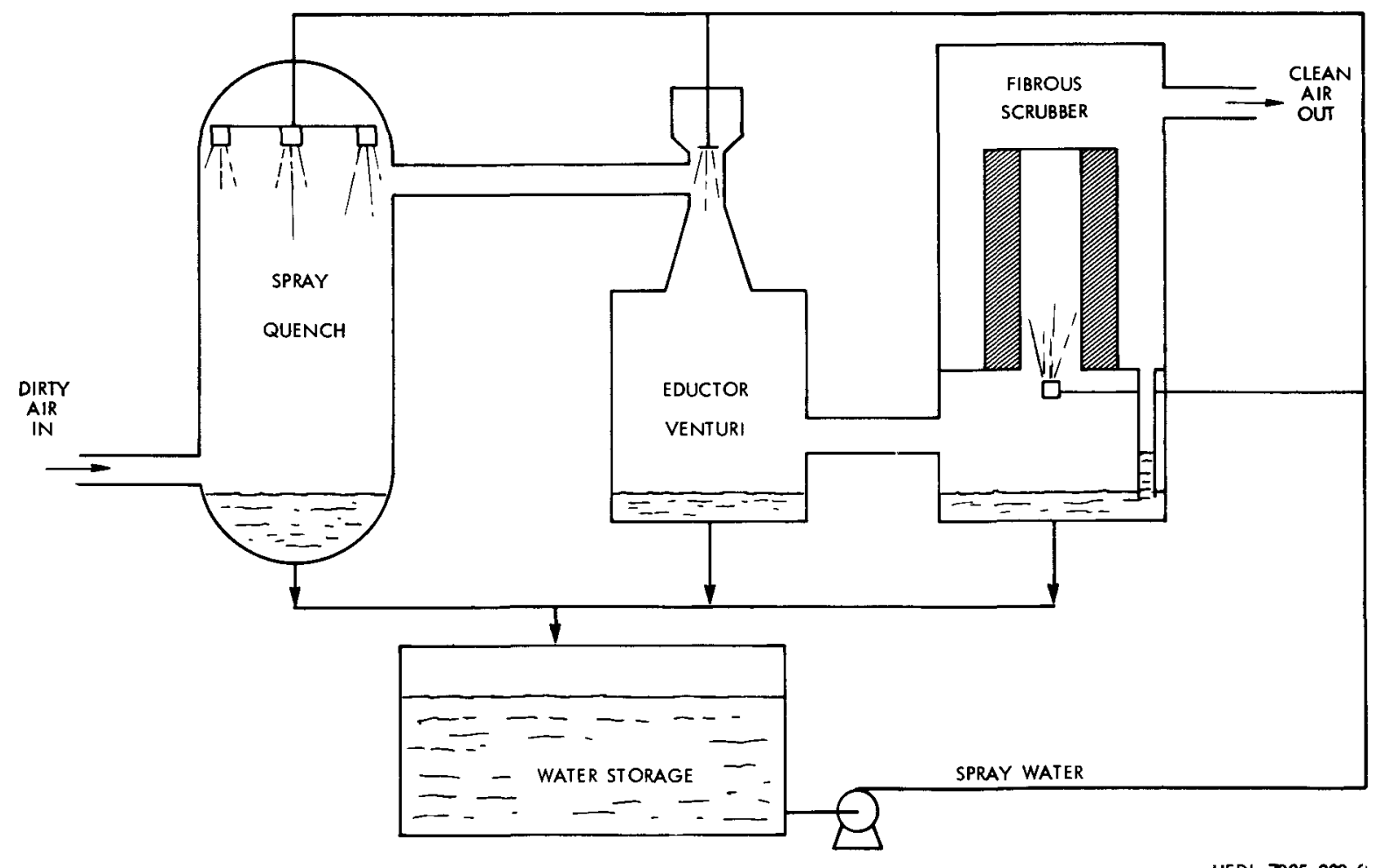

FIGURE 2. Schematic Diagram of Scrubber System Analyzed. 
The quench chamber acts to cool the incoming gases to about $50^{\circ} \mathrm{C}\left(120^{\circ} \mathrm{F}\right)$ and saturate the gas stream with water vapor. Large sodium compound particles are removed in the quench chamber and converted to a mist of sodium hydroxide. The aerosol mass associated with mist particles larger than about 2 micrometers diameter are removed in the venturi scrubber. An eductor venturi was chosen because of its small size, its minimal fan requirements, and because its removal efficiency increases with decreasing air flow rate.

The final air cleaning component is a fibrous bed scrubber which has a high removal efficiency for all sizes of particles. Diffusional capture, the efficiency of which increases as particles become smaller, is an important mechanism in the fibrous bed scrubber. The most penetrating particle size is about 0.4 microns in diameter, and even for this size a substantial fractional removal occurs. The ability of the fibrous bed scrubber to capture both the large and small ends of the size spectrum eliminates the possibility that a high fractional penetration could occur for an accident which led to very small aerosol particles.

It is worth restating that the question of behavior of condensible fission products arises because the scrubber rapidly cools the containment exhaust air. If an isothermal EACS (such as a filter) were used the gaseous fission products would remain as gases.

\section{VOLATILE FISSION PRODUCTS}

In the scenario for the core disruptive incident considered here, fission products enter the containment atmosphere as a result of sodium boil-off from the reactor cavity. Fission products in vapor form in the containment atmosphere are those with appreciable vapor pressures.

Three normally solid fission product forms whose vapor pressures are high enough to vaporize an appreciable fraction of the core inventory are 
$\mathrm{NaI}, \mathrm{SeO}_{2}$, and $\mathrm{Sb}_{2} \mathrm{O}_{3}$. The compounds which would actually exist in the post-accident containment atmosphere were not identified with certainty in the present study. The three possible forms cited above typify those assumed to be present.

\section{GAS COOLING RATE IN A WATER SPRAY}

Several cooling rates can be envisioned when hot gas enters a spray quench chamber. An average cooling rate might be estimated by looking at how rapidly gas in plug flow would cool as it passed through the quench chamber. Numerical calculations showed that for typical spray rates, and for an initial temperature difference (gas to spray) of $333^{\circ} \mathrm{C}$ $\left(600^{\circ} \mathrm{F}\right)$, the maximum gas cooling rate is about $350^{\circ} \mathrm{C} / \mathrm{sec}$.

In reality, the gas is not cooled by this average process, but undergoes a series of very rapid cooling and partial warming steps. The drops themselves remain cool by evaporation, and when air flows through the drop boundary layer, it is cooled from the bulk gas temperature to the boundary layer temperature in a distance smaller than the drop diameter. For gas entering the quench chamber with a $333^{\circ} \mathrm{C}\left(600^{\circ} \mathrm{F}\right)$ temperature difference, the gas in the boundary layer of $1-\mathrm{mm}$ diameter drops would cool at a rate of more that $700,000^{\circ} \mathrm{C} / \mathrm{sec}$. After leaving the boundary layer, the cooled gas would be rapidly warmed by hotter surrounding gas. Calculations indicate that most of the gas would flow through the drop boundary layers in the quench chamber, so virtually all of the aerosol would be subjected to a very high cooling rate. This favors homogeneous nucleation as opposed to condensation on sodium aerosol particles or spray drops. 


\section{APPROACH USED IN PRESENT STUDY}

\section{A. MODELING OF AEROSOL FORMATION AND REMOVAL}

\section{Nucleation}

Nucleation of gaseous materials was modeled by a simple analytical expression derived from a material balance. This expression permitted computation of the primary particle size of homogeneously nucleated aerosols. Agglomeration and removal of particles during the formation process were neglected.

\section{Agglomeration And Attachment}

The extremely high number concentration of freshly formed aerosol particles leads to rapid initial agglomeration. Agglomeration among the freshly generated particles was considered to take place in the first half of the quench chamber. Washout and attachment to sodium aerosol particles was neglected during the agglomeration phase. The very small size of the primary particles supports the plausibility of these two assumptions .

Attachment of agglomerated aerosol to sodium aerosol particles was considered to occur in the last half of the quench chamber. Attachment was attributed to diffusion of the freshly formed aerosol. Continuum theory was used to describe the diffusion process. The particle diffusivity was calculated from Einstein's equation which accounts for the particle Knudsen number.

\section{Particle Removal In Air Cleaning Components}

Two distinct particle populations were considered to undergo capture in the quench chamber, in the venturi scrubber, and in the wetted fiber bed. 
The agglomerated volatile particles were small in size and were removed to an appreciable extent only in the fiber bed. The sodium compound aerosol particles, on the other hand, were removed to an appreciable extent in the quench chamber and in the venturi scrubber.

Overall capture of freshly formed aerosol was computed by weighting the capture of the two particle populations by the mass fraction of fresh aerosol carried by the two populations. For most cases analyzed a large fraction of the fine aerosol was attached to sodium compound particles, so the penetration of all fission product, species was dominated by the penetration of the sodium aerosol.

\section{B. PARAMETRIC ANALYSIS}

It was recognized that the modeling approach used in this study was an approximate representation of the nucleation, agglomeration, and washout processes which would occur in the EACS. Therefore, important variables were treated as parameters to show how variations would affect the predicted removal efficiency. Important variables were identified from the several calculational models used.

Base-1ine parameter values were selected from accident calculations performed by others, and from available design information on the air cleaning system components. For all cases analyzed the dependent variable was the fractional penetration of freshly formed aerosol. 


\section{A. OVERALL SCHEMATIC RELATIONSHIP OF EACS TO CONTAINMENT SYSTEM}

The air cleaning system becomes a part of the containment system only for core disruptive accidents more severe than all design basis accidents. Another limitation is that the steel-walled containment vessel will not be opened to the EACS until 24 hours or more after the core disruptive incident has occurred. The containment and air cleaning components are depicted in Figure 3.

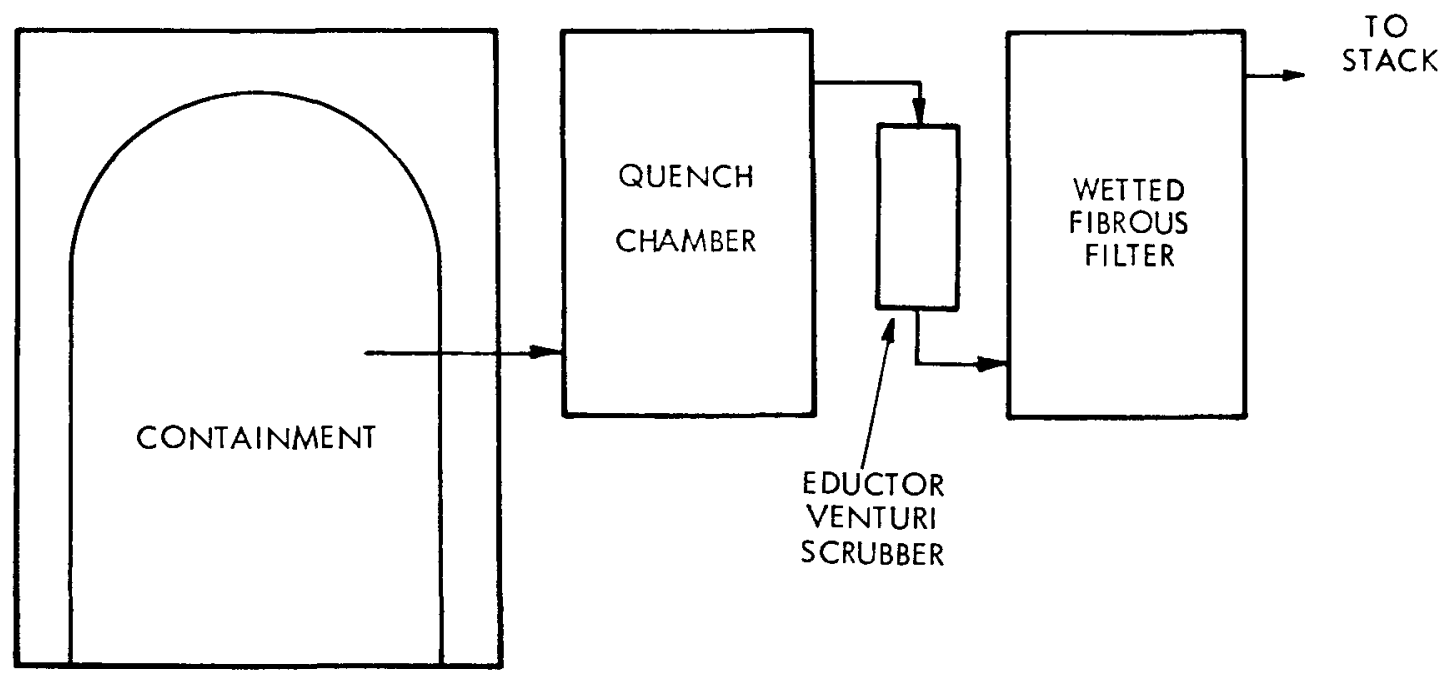

HEDL 7810-060.2

FIGURE 3. Schematic Diagram of EACS Application to Containment System.

\section{B. IMPORTANT EACS COMPONENTS}

1. Quench Chamber

In this study it was assumed that hot gases from the containment vesse 1 are cooled by water spray. This is done in a chamber, equipped at the top with a spray header. The arrangement is shown in Figure 4. 


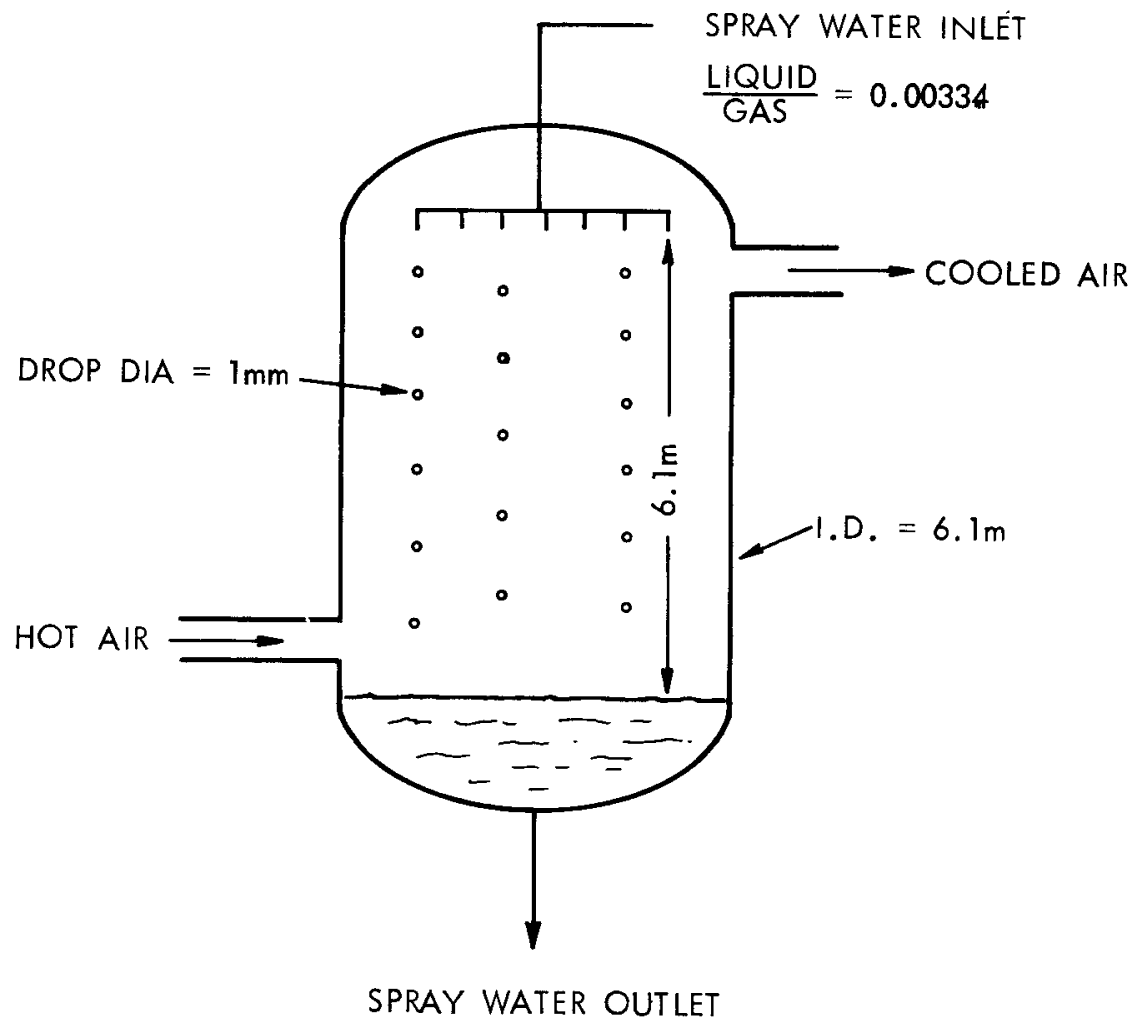

HEDL 7805-009.10

FIGURE 4. Quench Chamber

Liquid entering the quench chamber is atomized into $1 \mathrm{~mm}$ diameter drops, which fall $6.1 \mathrm{~m}(20 \mathrm{ft})$. Liquid flow rate was selected as 0.00334 of the gas flow rate $(25 \mathrm{gpm} / 100 \mathrm{cfm})$. Tank diameter was chosen as $6.1 \mathrm{~m}$ $(20 \mathrm{ft})$ to keep superficial gas velocity well below the terminal settling velocity of spray drops.

The numerical parameters specified here do not represent an engineered optimum design. Since a final design does not yet exist, reasonable estimates for design parameters were assigned on the basis of engineering judgment.

As described later in this report, spray chamber shape was treated as a parameter to show how spray fall height affected overall aerosol removal. 
In addition to gas cooling, appreciable washout of sodium aerosol occurs in the quench chamber. Impaction is the dominant drop capture process in the quench chamber, so only particles larger than 2 microns are removed to a significant extent. The pre-removal of large particles will cause the eductor venturi to exhibit a relatively low removal efficiency.

From the standpoint of fission product aerosol behavior, the main impact of the quench chamber is the formation and agglomeration of aerosol particles of condensible substances which entered as gases.

\section{Venturi Scrubber}

The second component of the air cleaning train shown in Figure 3 is an eductor venturi scrubber. The purpose of the venturi scrubber is to remove the major part of the aerosol mass, so that mist loading will not cause liquid blinding of the fibrous scrubber.

As shown in Figure 5, the eductor venturi is conceptually similar to a small spray chamber. Particle collection occurs by impaction onto high velocity water drops. The relative velocity between air and water drops was estimated from the water pressure drop using an orifice coefficient of 0.6. It was also assumed that the effective drop size was $1.5 \mathrm{~mm}$, the size expected for a hollow cone spray nozzle having the required flow capacity. The liquid flow rate was assigned a value of 0.00668 of the gas flow rate $(50 \mathrm{gpm} / 1000 \mathrm{cfm})$ and the distance over which scrubbing took place was estimated to be $1.53 \mathrm{~m}(5 \mathrm{ft})$. These assumptions permitted particle washout to be computed. Since fractional removal in the venturi scrubber was modest, changes in assumptions would have little impact on the analyses carried out in this study. 


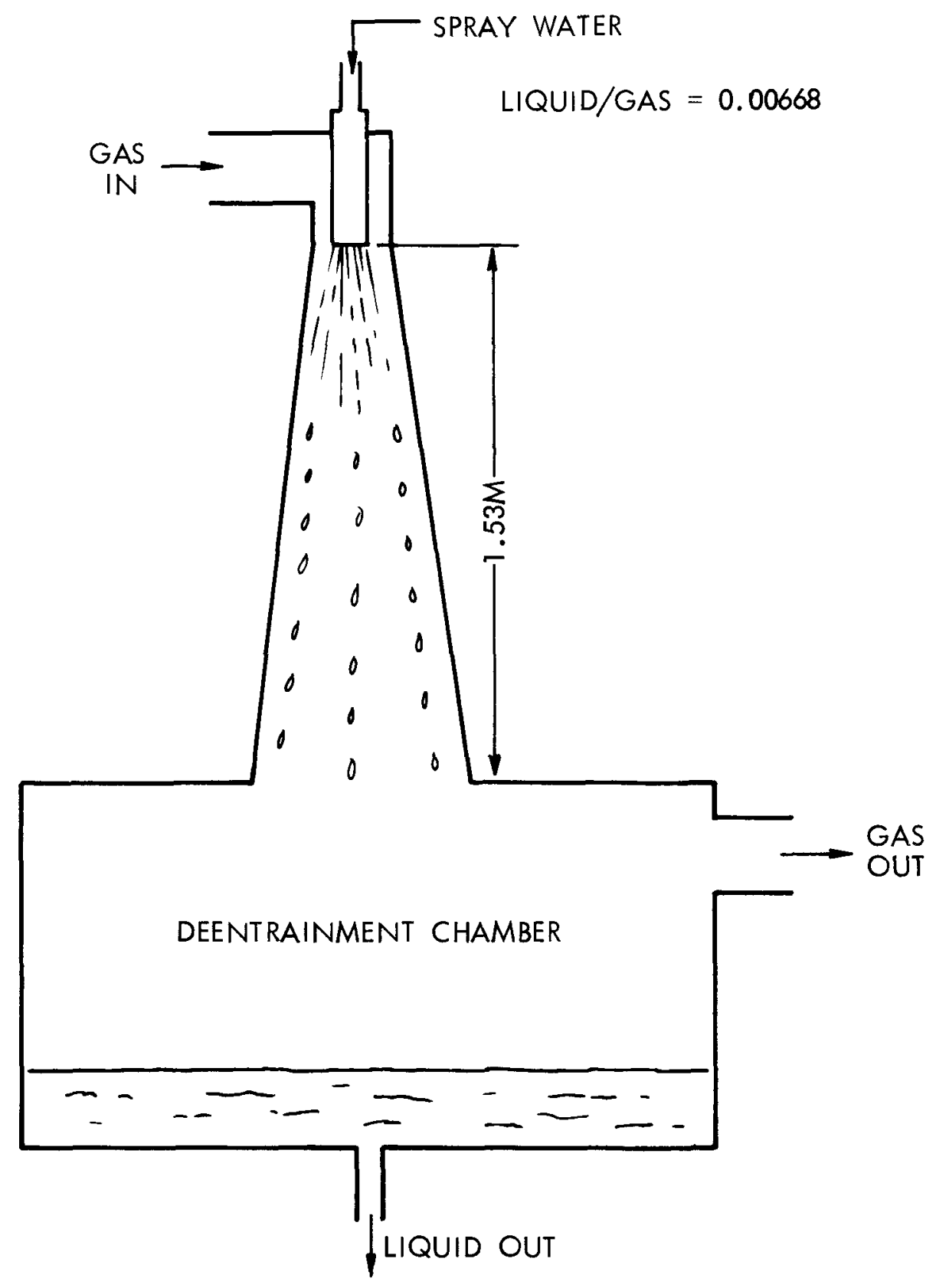

HEDL 7805-009.17

FIGURE 5. Eductor Venturi Scrubber. 


\section{Fibrous Bed Scrubber}

The final device in the air cleaning train is a fibrous bed scrubber. This device operates at low gas velocities, allowing diffusion to be a significant collection mechanism. The fibrous bed scrubber is shown in Figure 6.

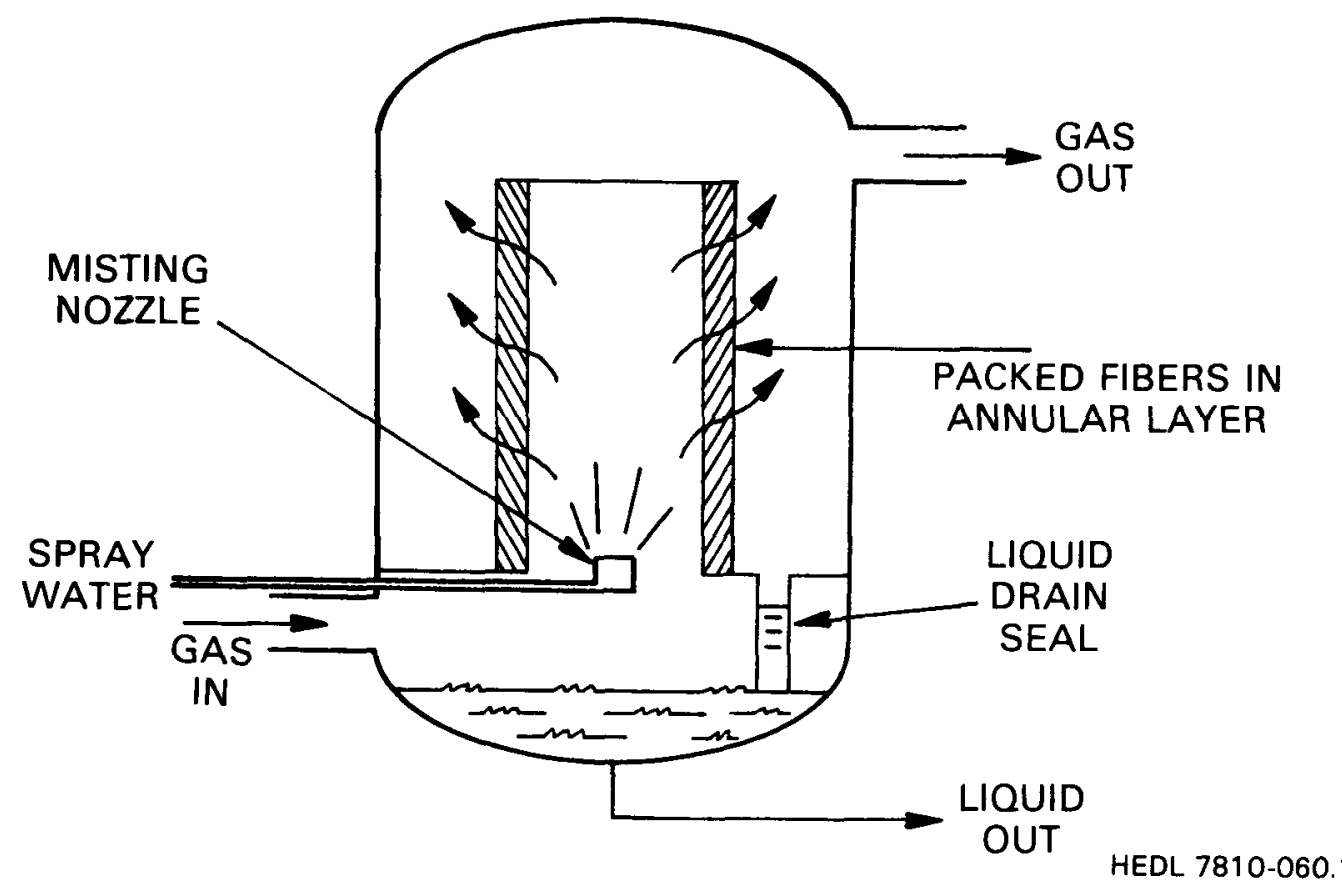

FIGURE 6. Fibrous Bed Scrubber.

A superficial gas velocity of $0.076 \mathrm{~m} / \mathrm{sec}(15 \mathrm{ft} / \mathrm{min}$ ) was assumed for the gas flow through the $76.2 \mathrm{~mm}$ (3-inch) bed of polypropylene fibers. Fiber size (20 micrometers) and bed porosity $(0.80)$ were assigned numerical values on the basis of measurements reported by Postma ${ }^{(2)}$.

Aerosol capture in the fibrous bed scrubber was modeled as a fibrous filtration process, and the presence of spray drops and liquid in the fiber bed were neglected. Three capture processes, diffusion, interception, and impaction were significant. 
VII. NUCLEATION AND FORMATION OF FISSION PRODUCT AEROSOL

\section{A. NUCLEATION FROM THE GAS PHASE}

When a gas is suddenly cooled, causing supersaturation of a gaseous component, it is experimentally observed that the supersaturated materials remain gaseous until a critical supersaturation is achieved. If the critical supersaturation level is exceeded, then very rapid condensation occurs and a fog is formed in the gas phase. The prior presence of particles in the gas phase reduces the critical supersaturation level.

Nucleation from gases has been studied extensively during the past 50 years, and the molecular processes which control nucleation are understood. The nucleation model used in the present study does not deal with the molecular aspects of nucleation, but is based on the known behavior of gaseous materials which are rapidly cooled and thereby supersaturated.

Several of the important concepts used in this work are described as follows. A recent study by Kennedy, et al. ${ }^{(3)}$ shows that homogeneous nucleation theory is capable of correctly predicting the size of $\mathrm{UO}_{2}$ aerosol formed when $\mathrm{UO}_{2}$ vapor is quenched by mixing with cool air. Kennedy's ${ }^{(3)}$ results support the plausibility of the approach adopted in the present study.

The free energy change which takes place when an ideal gas molecule condenses onto a drop of the same material is: ${ }^{(4)}$

$$
\Delta G=-n_{L} \frac{4}{3} \pi r^{3} k T \ln \frac{P}{P_{\infty}}+4 \pi \sigma r^{2}
$$

where $\Delta G=$ change in Gibbs free energy,

$$
\begin{aligned}
n_{L} & =\text { number of molecules per unit volume of liquid, } \\
r & =\text { radius of the liquid drop, } \\
k & =\text { Boltzmann's constant, }
\end{aligned}
$$




$$
\begin{aligned}
T= & \text { absolute temperature } \\
P / P_{\infty}= & \text { supersaturation }=\text { ratio of vapor pressure to equilibrium } \\
& \text { vapor pressure over a plane surface, } \\
\sigma= & \text { interfacial energy per unit area between liquid and vapor. }
\end{aligned}
$$

The graph of Equation (1), presented schematically in Figure 7, shows how one can judge whether a liquid embryo will grow or evaporate. From thermodynamic principles, any process will occur spontaneously only if the free energy change is negative. From Figure 7, such a change never occurs for $P<P_{\infty}$, which is consistent with the observation that drops always evaporate in an unsaturated vapor. However, when the vapor is supersaturated drops may either evaporate or grow spontaneously depending on the size. Drops larger than $r^{*}$ condense, and smaller drops evaporate.

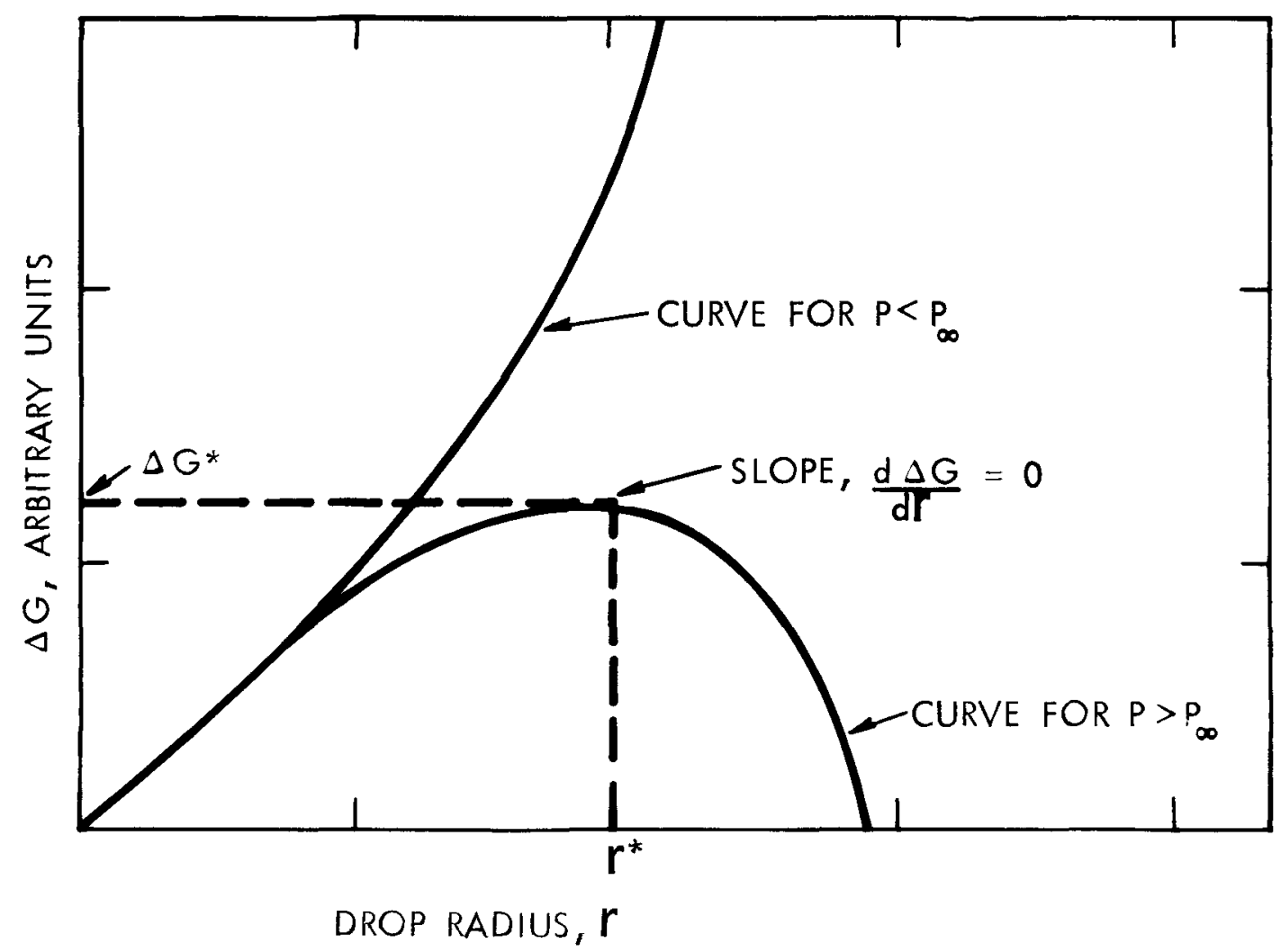

HEDL 7805-009.3

FIGURE 7. Free Energy Change for Drop Growth ${ }^{(4)}$. 
The critical radius, $r^{\star}$, can be found by differentiating Equation (1) with respect to $r$ and setting the derivative of $G$ equal to zero. Solving for $r *$ results in

$$
r^{*}=\frac{2 \sigma}{n_{L} k T \ln \frac{P}{P_{\infty}}}
$$

Similarly, the critical free energy may be calculated by substituting $r *$ from Equation (2) into Equation (1). The result is

$$
\Delta G^{*}=\frac{16 \pi \sigma^{3}}{3\left[n_{L} k T \ln \frac{P}{P_{\infty}}\right]^{2}}
$$

In a gas, there exist single molecules, doubles, triplets, and higher multiples ${ }^{(4)}$. The number per unit volume, at thermal equilibrium, can be computed from a Boltzmann distribution to be

$$
n(r)=n(I) \exp [-\Delta G(r) / k T]
$$

where $n(r)=$ number of embryos of radius $r$ /unit volume,

$n(I)=$ number of unassociated molecules/unit volume, $\Delta G(r)=$ free energy to form an embryo of radius $r$.

From Equation (4), the number of embryos of radius $r^{*}$ per unit volume of gas is:

$$
n\left(r^{*}\right)=n(I) \exp \left[-\Delta G^{*} / k T\right]
$$

Whenever one of the critical embryos collides with another molecule the embryo will be larger than the critical size, and will grow spontaneously. Therefore the nucleation rate, defined as the rate at which critical embryos collide with single gas molecules, can be computed from Equation (5), and the collision rate per drop. From kinetic theory, the molecular collision rate per unit area is $(4)$ 


$$
\frac{\text { collision rate }}{\text { unit area }}=\frac{P}{(2 \pi \mathrm{mkT})^{1 / 2}}
$$

where $P=$ pressure of the vapor,

$$
\mathrm{m}=\text { mass of vapor molecule. }
$$

Taking the embryo area as $4 \pi r^{* 2}$, the rate at which critical embryos collide with gas molecules is

$$
J=\frac{4 \pi P r^{\star 2}}{(2 \pi m k T)^{T / 2}} n(I) \exp \left(-\Delta G^{*} / k T\right)
$$

where $J=$ nucleation rate per unit volume of gas.

This simple nucleation theory has neglected the fact that evaporation from the critical embryo is also a possibility. The nucleation rate defined in Equation (7) should be multiplied by

$$
\left(\frac{\ln \frac{P}{P_{\infty}}}{8 r^{\star 3} n_{L}}\right)^{1 / 2}
$$

to account for the evaporation ${ }^{(4)}$. According to Fletcher (4) this factor is numerically approximately 0.1 , which is a minor factor in nucleation rate calculations.

An example calculation of nucleation rate for water at atmospheric temperatures and pressures, presented by Fletcher $(4)$, 11 lustrates the theoretical calculations. The nucleation rate predicted by Equation (7) is graphed in Figure 8 .

The most important behavior exhibited in Figure 8 is the very rapid change in nucleation rate with saturation ratio. Similarly shaped curves would be expected for other condensible vapors. The position of the curves would depend on physical properties such as surface energy, liquid 
density, vapor pressure, etc.

Experiments carried out by Japanese ${ }^{(5)}$ and Dutch ${ }^{(6)}$ workers show that homogeneous nucleation of sodium vapor does not occur until supersaturations of 15 to 40 are achieved. When fog formation occurred at lower saturation ratios, it was attributed to the presence of foreign particles serving as nuclei.

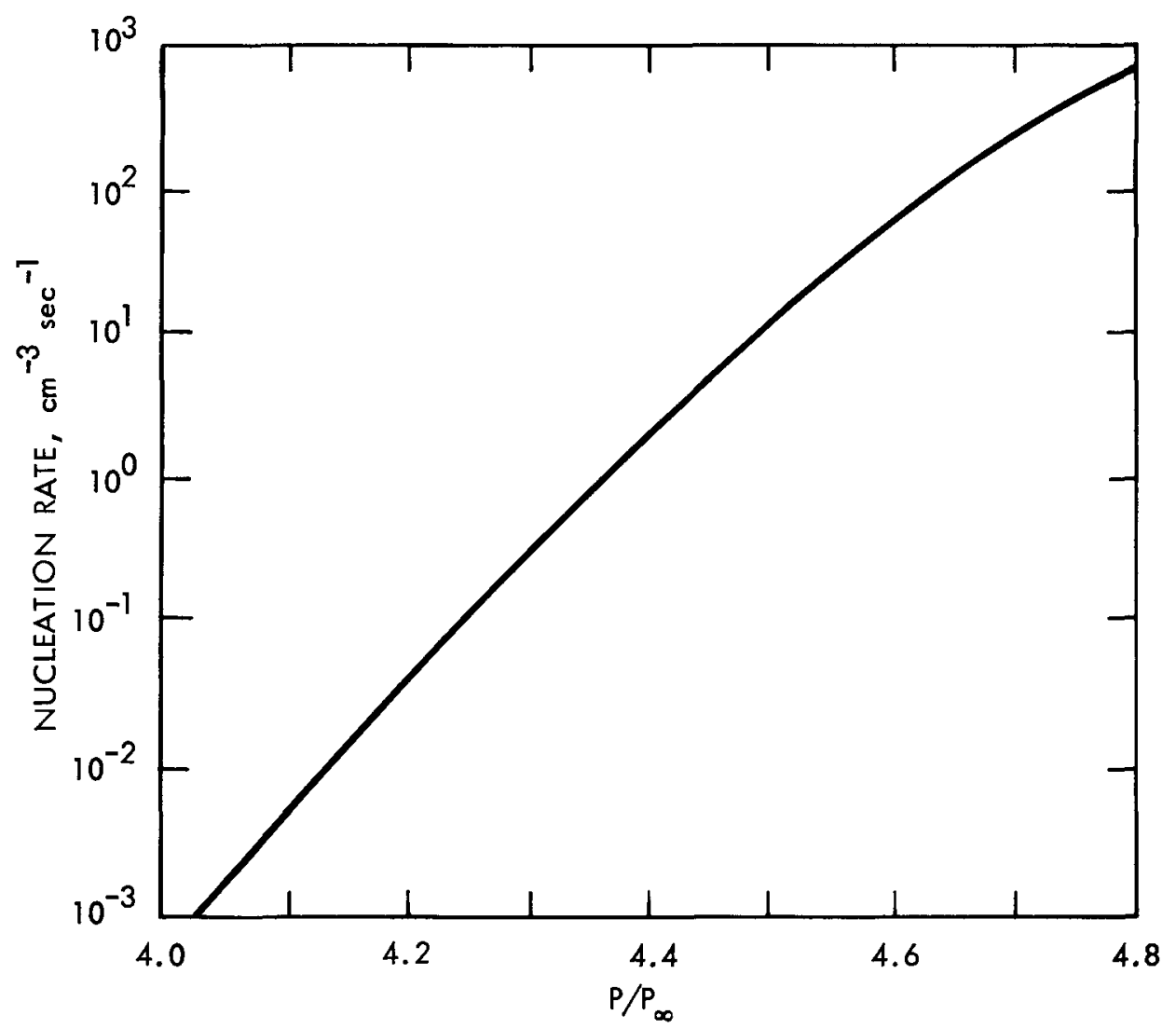

HEDL $7805-009.4$

FIGURE 8. Nucleation Rate For Water Vapor as a Function of the Saturation Ratio ${ }^{(4)}$.

For condensible fission products, it is apparent that homogeneous nucleation would occur if supersaturations larger than a critical value were achieved in the quench chamber. The critical supersaturations are not known with certainty, but they would likely fall in the range of 4 to 50 . 
The lowering in supersaturation required to nucleate a vapor in the presence of insoluble particles has been studied by Fletcher ${ }^{(4)}$. When nucleation takes place on an insoluble surface, the embryo is envisioned to take the shape of a spherical cap, as shown in Figure 9.

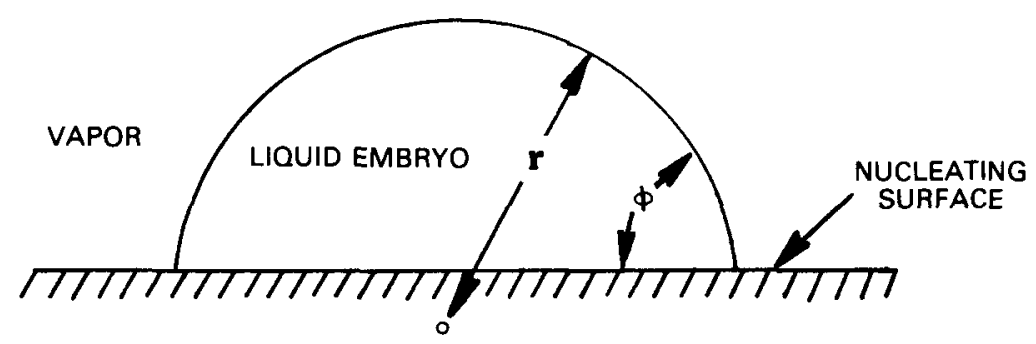

FIGURE 9. Nucleation in the Presence of an Insoluble Surface.

For mechanical equilibrium to exist, the surface forces must be balanced. The angle depicted in Figure 9 is related to interfacial tensions by ${ }^{(4)}$

$$
\cos \phi=\frac{\left(\sigma_{C V}-\sigma_{C L}\right)}{\sigma_{L V}}
$$

where $\phi=$ contact angle shown in Figure 9,

$\sigma_{C V}=$ interfacial energy between surface and vapor,

${ }^{\sigma} \mathrm{CL}=$ interfacial energy between surface and liquid,

$\sigma_{L V}=$ interfacial energy between 1 iquid and vapor.

The presence of the solid surface lowers the energy barrier to nucleation. Fletcher's ${ }^{(4)}$ result for the effect of contact angle on critical saturation is presented in Figure 10.

For contact angles smaller than $20^{\circ}$, vapors condense with virtually no supersaturation required. On the other end of the spectrum the surface 
has little effect, and nucleation takes place at only the supersaturation levels required for homogeneous nucleation.

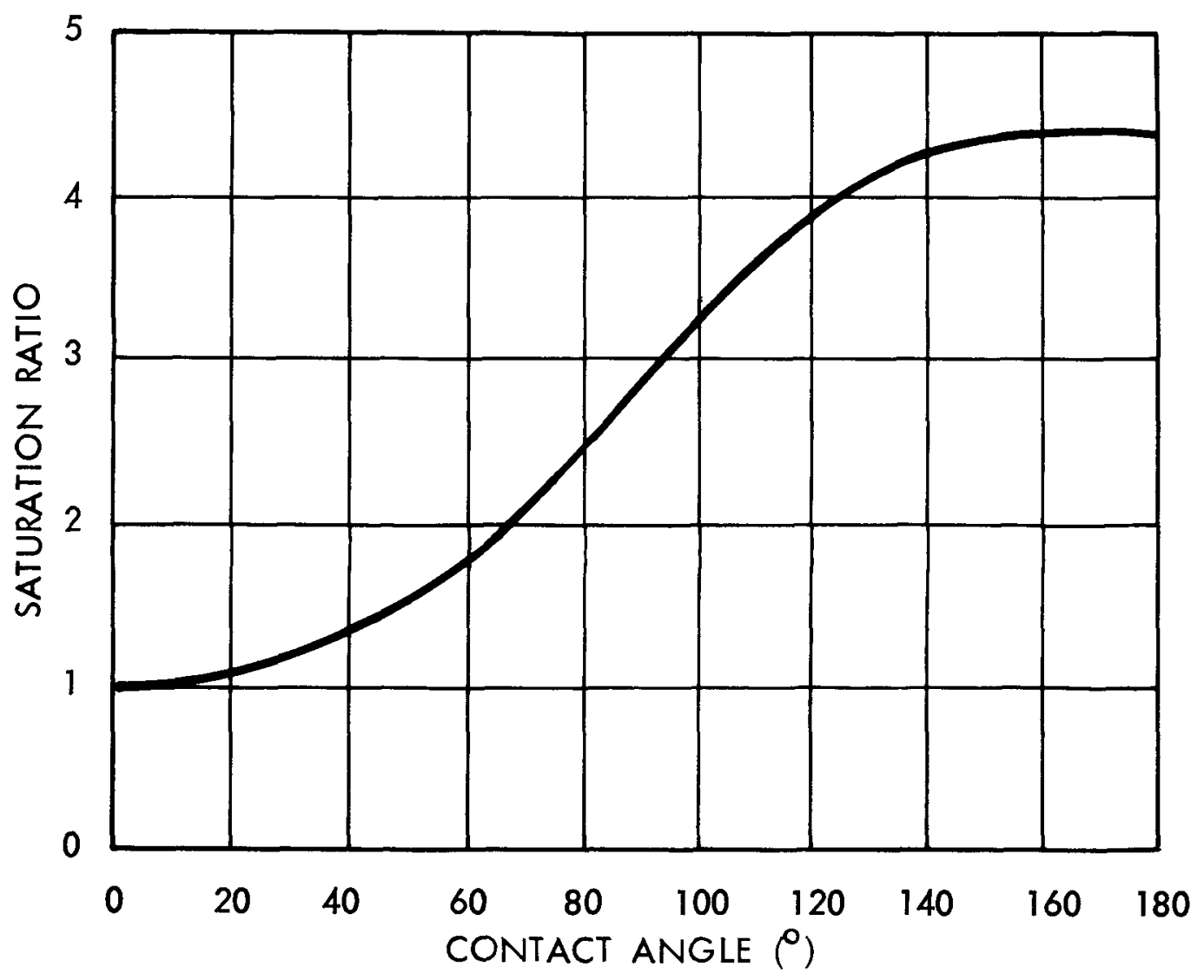

HEDL 7805-009.2

FIGURE 10. Critical Saturation Ratio for $\mathrm{J}=1 \mathrm{~cm}^{-2} \mathrm{sec}^{-1}$ Upon a Plane Substrate of Given Contact Angle, at $0^{\circ} \mathrm{C}$.

Fletcher (4) has extended heterogeneous nucleation theory to apply to small particles, where the radius of curvature has an effect on the vapor pressure. Without presenting the details of his derivation, we present typical results of Fletcher's ${ }^{(4)}$ theory in Figure 11. 


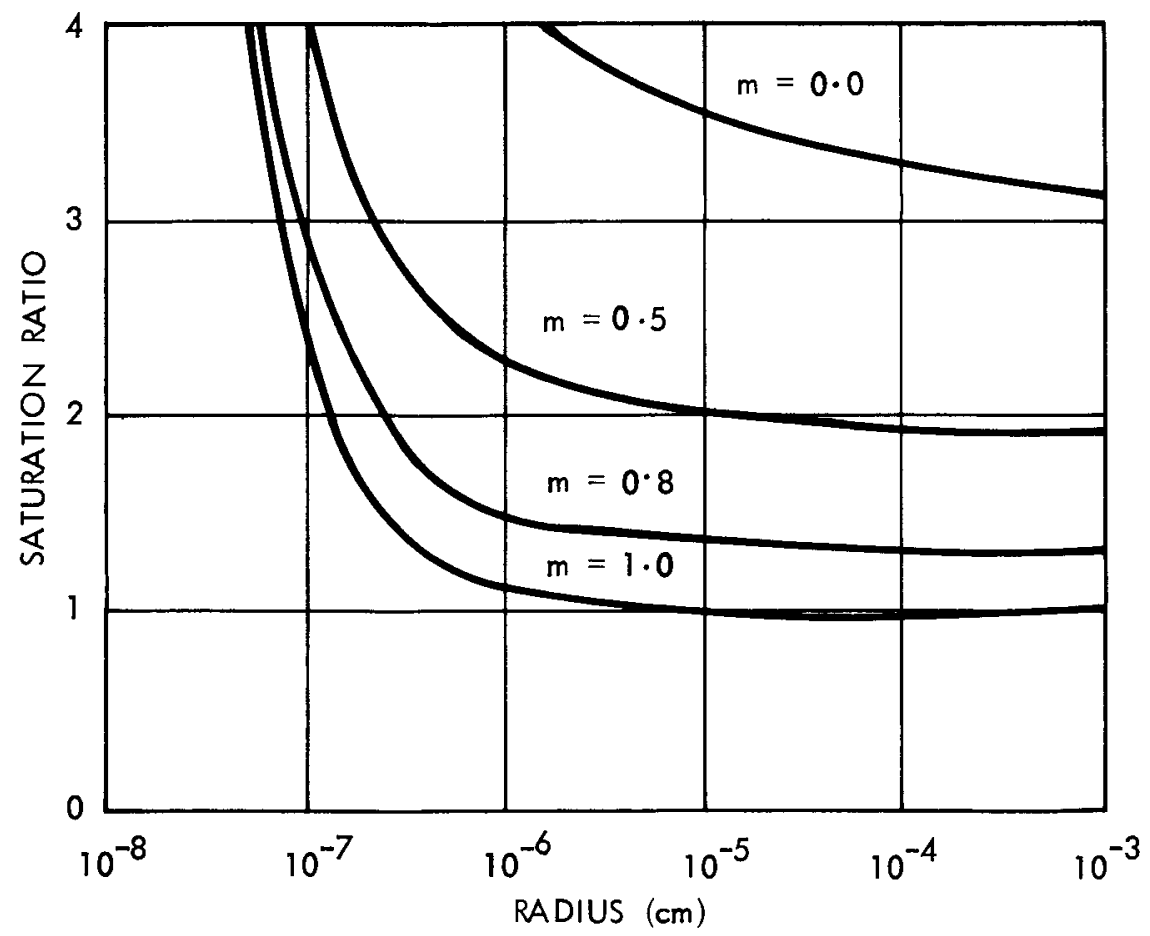

HEDL 7805-009.1

FIGURE 11. Critical Saturation Ratio for Nucleation of a Water Droplet in One Second Upon a Particle of Given Radius and with Surface Properties Defined by $\mathrm{m}=\cos \phi$.

Figure 11 shows that particles must be larger than about $10^{-7} \mathrm{~cm}$ in radius to serve as good nuclei, and that particles with large contact angles $(m=0)$ do not greatly enhance nucleation.

As applied to the present study the following significant nucleation phenomena are evident.

- At a critical supersaturation level, the nucleation rate increases very rapidly with supersaturation.

- The numerical value of critical supersaturation is dependent on the physical properties of the nucleating substance. Available data suggest that for condensible fission products, homogeneous nucleation occurs at supersaturation in the range of 4 to 50 . 
- The presence of sodium aerosol particles favors nucleation. The degree of enhancement depends on particle size and on wetting angles. In the limit, the critical supersaturation level is reduced to unity.

\section{B. EQUATIONS FOR COMPUTING SUPERSATURATION IN A COOLING GAS}

Based upon the general characteristics of nucleation described in previous paragraphs, it was decided that a knowledge of the supersaturation level as a function of time would provide enough information to determine whether homogeneous nucleation would occur, and the number concentration of nuclei formed per unit volume of gas. A material balance on a volatile material in a parcel of gas undergoing cooling, as shown schematically in Figure 12, can be written as follows

$$
\begin{aligned}
& \text { Input Rate }=0 \\
& \text { Output Rate }=K\left(C-C_{s}\right) \\
& \text { Accumulation Rate }=\frac{d C}{d t}
\end{aligned}
$$

From conservation of mass,

$$
\frac{d C}{d t}=K\left(C-C_{s}\right)
$$

$$
\text { where } \begin{aligned}
C & =\text { vapor concentration in gas, } \\
C_{S} & =\text { saturated vapor concentration, } \\
K & =\text { diffusional deposition constant. }
\end{aligned}
$$


Equation (9d) can be re-written in terms of the supersaturation ratio, $B$. $B$ is defined by

$$
B=\frac{C}{C_{s}}
$$

substituting B from Equation (10) into Equation (9) results in

$$
\frac{d B}{d t}+B\left[\frac{1}{C_{s}} \frac{d C_{s}}{d t}+k\right]=k
$$

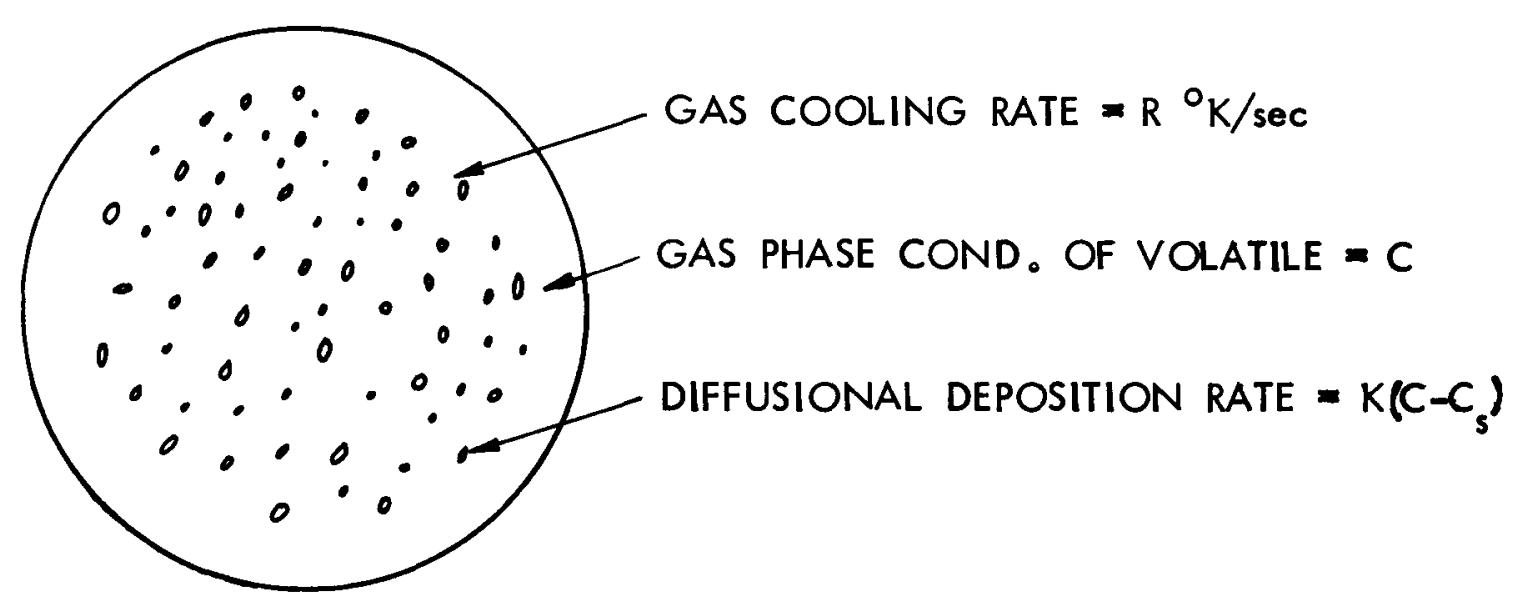

HEDL 7805-009.2a

FIGURE 12. Cooling and Supersaturation of Gas Parcel.

The saturated concentration, $C_{S}$, may be related to temperature using

$$
c_{S}=\frac{E}{T} \exp -\frac{A}{T}
$$

where $E=a$ constant,

$$
\begin{aligned}
& A=a \text { constant } \\
& T=\text { absolute temperature. }
\end{aligned}
$$


Since $\frac{d C_{s}}{d t}=\frac{d C_{s}}{d T} \frac{d T}{d t}$ and $\frac{d T}{d t}=R$, we can write

$$
\frac{1}{C_{s}}\left[\frac{d C_{s}}{d t}\right]=-\frac{R}{T}\left[\frac{A}{T}-1\right]
$$

where $\mathrm{R}=$ cooling rate, ${ }^{\circ} \mathrm{K} \mathrm{sec}^{-1}$.

If Equation (13) is substituted into Equation (11), and $\frac{d}{d t}$ replaced by

$\frac{d}{d T} \frac{d T}{d t}$, Equation (11) can be written as

$$
\begin{gathered}
\frac{d B}{d t}+B \alpha=\frac{K}{R} \\
\text { where } \alpha=\frac{1}{T}\left[\frac{A}{T}-1\right]-\frac{K}{R}
\end{gathered}
$$

Equation (14) can be linearized and easily solved analytically by treating the multiplier of $B$ in Equation (14) as a constant. The solution of Equation (14), taking the coefficient of $B$ as constant, is

$$
B=\left[B_{0}+\frac{K}{R \alpha}\right] \exp -\alpha\left[T-T_{0}\right]-\frac{K}{R \alpha}
$$

where $B=$ supersaturation of the end of a temperature step,

$B_{0}=$ supersaturation at the beginning of step,

$\left(T-T_{0}\right)=$ increment in temperature for step,

$K=$ diffusional deposition constant,

$\mathrm{R}=$ cooling rate,

$A=$ constant in vapor pressure equation. 
In using Equation (15), the value of $\alpha$ should be evaluated at the average temperature for the step. Also, $T-T_{0}$ should be kept small so that $\alpha$ does not vary much from beginning to end.

Predictions based on Equation (15) were made for sodium iodide. The airborne concentration was equated to that which would exist if $100 \%$ of core iodine inventory was present in the containment atmosphere as $\mathrm{NaI}$ vapor. From the measurements of Cogin and Kimbal1 ${ }^{(7)}$, the value of $A$ was found to be 25,264 , and the air would be saturated at $810^{\circ} \mathrm{K}$. Results of the calculation are presented in Figure 13.

From the curves presented in Figure 13, it is apparent that nucleation would not occur for $K / R$ values as large as 1.0. On the other hand for $K / R$ smaller than about 0.1 , supersaturation levels higher than the critical value would be reached and nucleation would be expected.

The range of uncertainty in the critical supersaturation level is not very important because for $K / R$ values between 1 and 0.1 increasing or decreasing the critical supersaturation merely increases or decreases the temperature at which nucleation would commence.

For cases where no foreign particles were present, homogeneous nucleation would proceed until $K / R=0.1$ is approximately satisfied. This information can be used to estimate a particle number concentration and a particle size. This is so because $K$, the deposition constant, can be related to particle size and number concentration by diffusion theory. If the uptake rate of vapor by particles is equated to the steady state uptake by spheres, $K$ can be related to particle size and concentration by

$$
K=\frac{12 D C_{A}}{d^{2} \rho}
$$




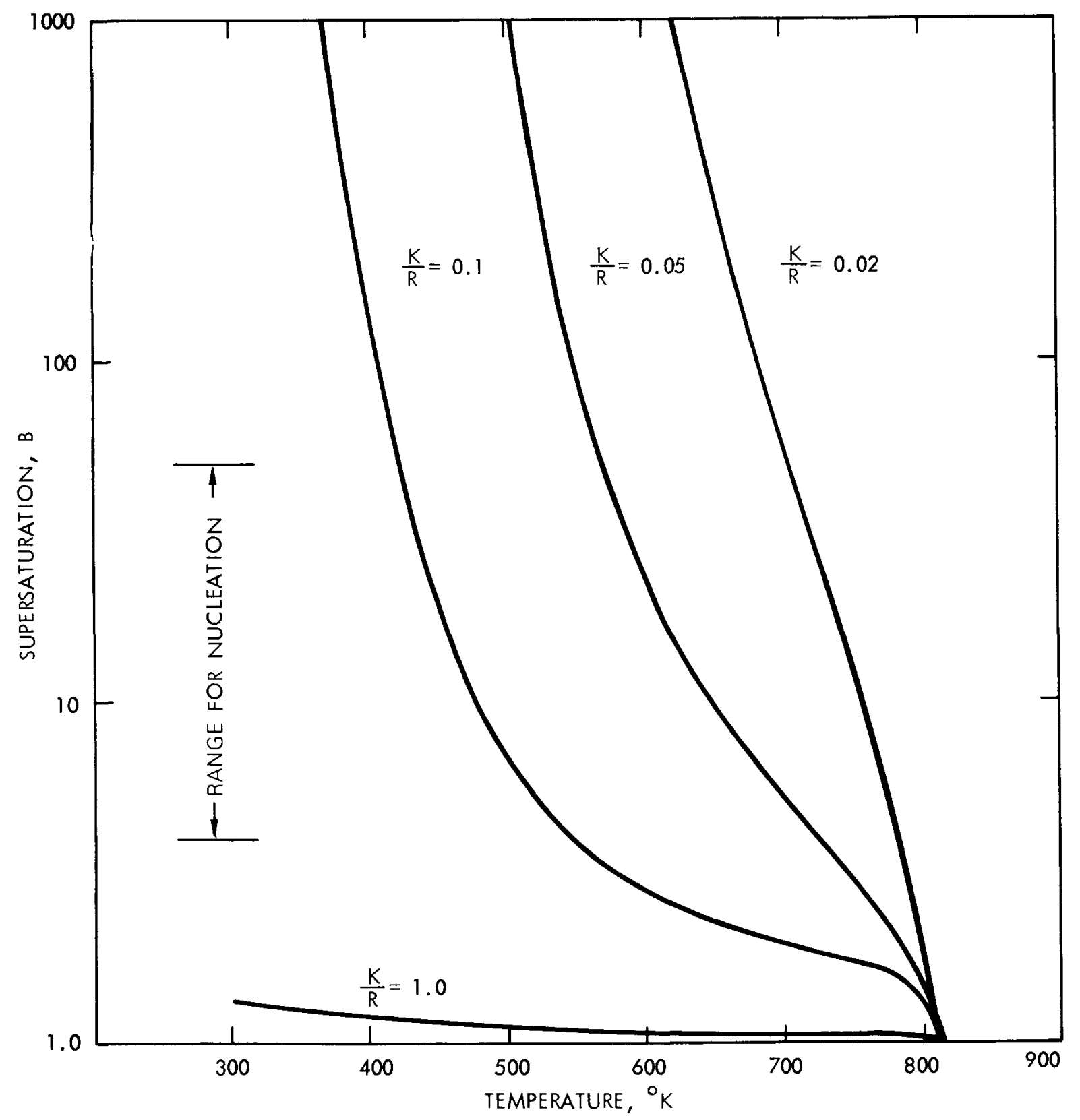

HEDL 7805-009.12

FIGURE 13. Supersaturation Achieved When $\mathrm{NaI}$ is Cooled in the Presence of Sodium Aerosol. 


$$
\text { where } \begin{aligned}
K & =\text { vapor uptake constant, } \mathrm{sec}^{-1}, \\
D & =\text { vapor diffusivity, } \mathrm{cm}^{2} / \mathrm{sec}, \\
C_{A} & =\text { aerosol mass concentration, } \mathrm{g} / \mathrm{cm}^{3} \\
d & =\text { particle diameter, } \mathrm{cm}, \\
\rho & =\text { particle density, } \mathrm{g} / \mathrm{cm}^{3} .
\end{aligned}
$$

Equation (16) applies for uniformly sized primary particles. For log-normally distributed primary particles, $K$ is given by

$$
K=\frac{12 D C_{A} d_{10}}{\rho d_{30}^{3}}
$$

$$
\text { where } \begin{aligned}
d_{10} & =\text { number mean diameter } \\
d_{30} & =\text { volume mean diameter }
\end{aligned}
$$

Heterogeneous nucleation will dominate if the foreign particle population yields a $K$ value large enough so that $K / R$ exceeds 0.1 or so. Thus it is predicted that whether homogeneous or heterogeneous nucleation occurs is dependent on the initial particle size and concentration and on the cooling rate $R$.

\section{COOLING RATE EXPERIENCED IN SPRAY QUENCH CHAMBER}

A spectrum of cooling rates is encountered by gases passing through a spray quench chamber. Perhaps the simplest to visualize is the bulk cooling rate. If one equates the heat transfer rate to drops to the rate of loss of sensible heat, the result is

$$
h A\left(T-T_{s}\right)=\rho C_{p} \frac{d T}{d t}
$$


where $h=$ heat transfer coefficient to drops,

$$
\begin{aligned}
A & =\text { drop interfacial area/unit volume of gas, } \\
\rho & =\text { gas density, } \\
C_{p} & =\text { gas heat capacity, } \\
T & =\text { gas temperature, } \\
T_{s} & =\text { temperature of drop surface. }
\end{aligned}
$$

Cooling rates predicted from Equation (18) vary from near zero at the outlet, to about $350^{\circ} \mathrm{K} / \mathrm{sec}$ at the inlet to the quench chamber. This maximum cooling rate was computed for base case parameters: drop diameter of 1000 micrometers, spray flow/gas flow of 0.00334 , and an initial temperature difference of $361^{\circ} \mathrm{K}\left(650^{\circ} \mathrm{F}\right)$. This average cooling rate is appreciably smaller than cooling rates experienced by gas which flows through the drop boundary layer.

Gas flow around a sphere is depicted in Figure 14. A parcel of gas entering the flow field around the drop is not cooled until it enters the boundary layer. Since the boundary layer is thin, and the gas velocity is appreciable, rapid cooling occurs. In order to obtain a rigorous estimate of the cooling rate, one could solve the velocity and temperature field equations, and compute the cooling rate experienced along various stream lines. We have made a first approximation to an average cooling rate in the boundary layer by making the following assumptions:

- The gas undergoes a temperature drop of $\frac{1}{2}\left(T_{b}-T_{s}\right)$.

- The distance over which the cooling occurs $=\frac{1}{2}(d)$.

- Average gas velocity $=\frac{1}{2}$ (drop falling velocity).

Using these assumptions, the cooling rate may be computed as

$$
\frac{\Delta T}{\Delta t}=\frac{\left(T_{b}-T_{s}\right)}{2} \cdot \frac{2}{d} \cdot \frac{V_{t}}{2}=\frac{\left(T_{b}-T_{s}\right) V_{t}}{2 d}
$$




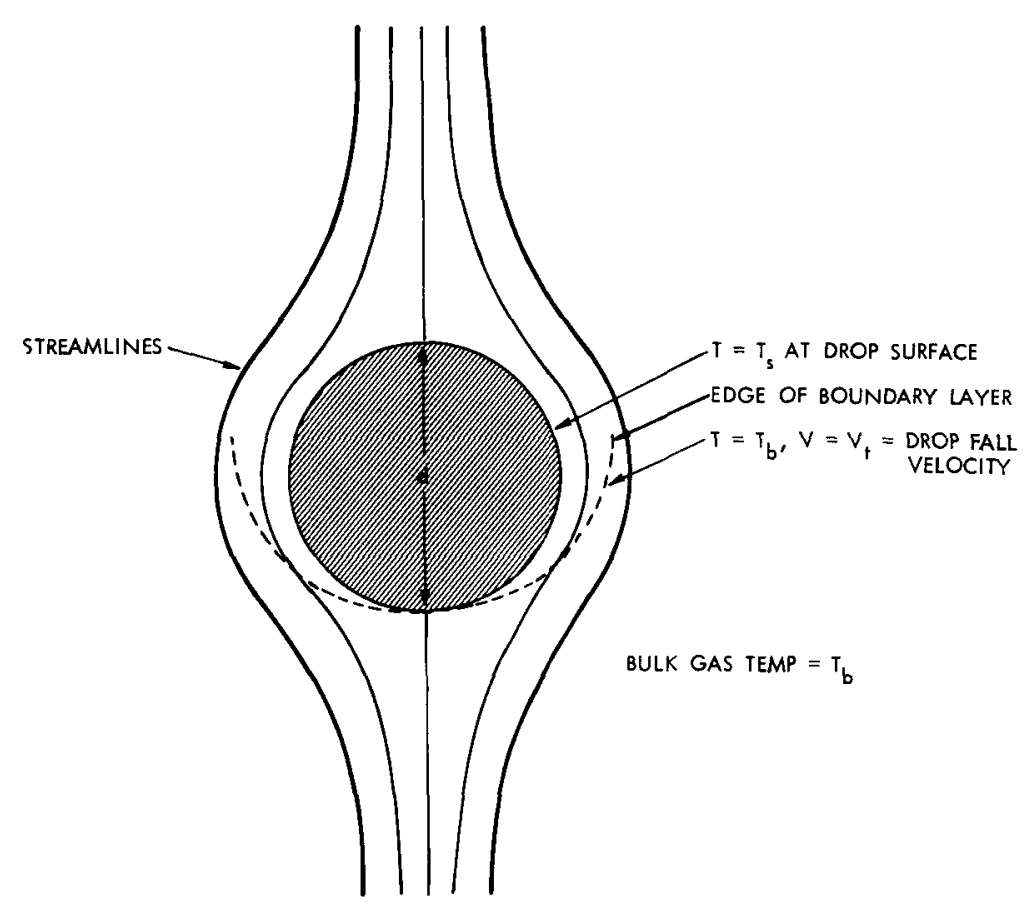

HEDL $7805-009.8$

FIGURE 14. Boundary Layer Around Falling Drop.

For a 1000 micron diameter spray drop falling at terminal velocity of $4 \mathrm{~m} / \mathrm{sec}$, and for a temperature difference of $361^{\circ} \mathrm{K}\left(650^{\circ} \mathrm{F}\right)$, the cooling rate predicted from Equation (19) is

$$
\frac{361(4)}{2(0.001)}=7.2 \times 10^{5}{ }^{\circ} \mathrm{K} / \mathrm{sec}
$$

This cooling rate is more than 2000 times greater than the maximum bulk value predicted by Equation (18), and shows that nucleation of condensible vapors would be favored in drop boundary layers.

The fraction of the air flow which passes through drop boundary layers was estimated from values of boundary layer thickness ${ }^{(8)}$, from average 
boundary layer velocity (half the terminal velocity), and from the number of drops falling per unit time. For typical quench chamber parameters, it was calculated that all of the gas passed through drop boundary layers for each $1.2 \mathrm{ft}$ of chamber height. In essence, all of the cooled gas passes through drop boundary layers, and is exposed to the rapid cooling rates typified by Equation (19). Therefore homogeneous nucleation would be expected for $K / R$ values smaller than 0.1 , with $R$ being of the order of $7 \times 10^{5}{ }^{\circ} \mathrm{K} / \mathrm{sec}$. This means that homogeneous nucleation will occur unless $K$ values are larger than $7 \times 10^{4} \mathrm{sec}^{-1}$.

\section{SIZE OF NUCLEATED PARTICLES}

The size and concentration of nucleated particles can be estimated from Equation (17) by assigning a $K / R$ value 0.1 , and setting the aerosol mass concentration equal to the vapor concentration in hot gas. The logic of using a $K / R$ value of 0.1 is that homogeneous nucleation will continue until diffusional deposition on the formed particles can limit the degree of supersaturation in surrounding gas. From the discussion presented earlier in this report, this occurs when $K / R$ is smaller than about 0.1 . Equating the mass concentration of nucleated particles to the mass concentration of condensible vapor implies that all vapor has condensed. This is quite realistic because vapor pressures change exponentially with temperature, and large changes in termperature are experienced when hot gas passes through a drop boundary layer.

Since $K / R=0.1$, and $R=7 \times 10^{5}$, the value of $K$ is about $7 \times 10^{4}$. Setting this equal to the value defined in Equation (17) results in

$$
K=7 \times 10^{4}=\frac{12 \mathrm{DC}_{A} d_{10}}{\rho d_{30}^{3}}
$$

As a typical result, we estimated $C_{A}$ to have a value of $2.91 \times 10^{-4} \mathrm{~g} / \mathrm{m}^{3}$ for $\mathrm{NaI}$ saturated at $700^{\circ} \mathrm{K}\left(800^{\circ} \mathrm{F}\right)$. From Equation (17), $d_{30}$, the mass mean diameter was estimated to have a value of $1.12 \times 10^{-7}\left(\rho=0.92 \mathrm{~g} / \mathrm{cm}^{3}\right)$. 
The number concentration for this freshly agglomerated aerosol is very high, $4.3 \times 10^{11}$ particles $/ \mathrm{cm}^{3}$. These particles would coagulate very rapidly until the number concentration was reduced by several orders of magnitude. The final number concentration was computed from the Brownian coagulation equation ${ }^{(9)}$ :

$$
n=\frac{n_{0}}{1+n_{0} K_{0} t}
$$

where $n=$ particle number concentration after time, $t$,

$n_{0}=$ particle number concentration at time, $t,=0$,

$\mathrm{K}_{\mathrm{o}}=$ coagulation constant,

$t=$ time period for coagulation.

Ko was computed from $(9)$

$$
\begin{aligned}
\mathrm{K}_{0}=\frac{8 \mathrm{~K} T}{6 \mu}\left[1+\mathrm{A} \frac{\ell}{r}+Q \frac{\ell}{r} \rho^{-b r / \ell}\right] \\
\text { where } \mathrm{K}_{0}=\text { coagulation constant, } \\
\mathrm{K}=\text { Boltzmann's constant, } \\
T=\text { absolute temperature, } \\
\mu=\text { gas viscosity } \\
\mathrm{A}=\text { a constant }=1.246, \\
\ell=\text { gas molecule mean free path, } \\
r=\text { particle radius, } \\
Q=\text { a constant }=0.034, \\
\mathrm{~b}=\text { a constant }=0.87 .
\end{aligned}
$$


Agglomeration time, $t$, was equated to the transit time of the gas in the first one-half of the quench chamber. For the particle concentration involved here, it was found that $n_{0} k_{0} t$ was much larger than unity, so Equation (20) may be simplified to

$$
n=\frac{1}{K_{0} t}
$$

Thus the final aerosol number concentration is independent of the initial concentration, a fact which means that errors in $n_{0}$ have little effect on the final number concentration. From a mass balance, the final particle size can be related to aerosol mass concentration:

$$
C_{A}=n \rho \frac{\pi}{6} d_{30}^{3}
$$

The density of the agglomerated particles was computed from the material density using a density modification factor of $0.25(10)$. For $\mathrm{NaI}$, the agglomerated particle density was $0.25(3.667)=0.92 \mathrm{~g} / \mathrm{cm}^{3}$.

Since $K_{0}$ varies with particle size, Equations (17), (21), (22), and (23) were solved iteratively, basing $k_{0}$ on the arithmetic mean between the initial $d_{30}$ and the final $d_{30}$. Mass mean diameters of agglomerated aerosol varied from 0.015 to 0.078 micrometers, depending on the mass concentration of condensible vapor. For the base case where $\mathrm{NaI}$ was saturated at $700^{\circ} \mathrm{K}\left(800^{\circ} \mathrm{F}\right)$ the mass mean diameter was predicted to be 0.023 micrometers. It was assumed that $\sigma_{g}$, the geometric standard deviation, was equal to 2.0 , and that the distribution was log-normal. 


\section{ATTACHMENT OF NUCLEI TO SODIUM AEROSOL}

\section{A. MODEL FOR ATTACHMENT PROCESS}

The small particles (nuclei) of condensed vapors have fairly high diffusivities and will co-agglomerate with other aerosol particles. A simple model of the attachment process was developed to predict the fraction of aerosol which would co-agglomerate with the sodium aerosol. After agglomeration, two distinct aerosol populations would exist: (a) the nuclei of condensed vapors, and (b) the sodium compound aerosol. Behavior of the two populations in downstream air cleaning components would be different because of significant differences in particle size.

Attachment of the nuclei to sodium aerosol was modeled as a diffusion process. For steady state diffusion to an isolated sphere, the uptake rate was derived to be

$$
\text { Uptake rate }=\frac{\left[C_{s}-C_{\infty}\right] 4 \pi D}{\left[\frac{1}{r}-\frac{1}{r_{\infty}}\right]}
$$

$$
\text { where } \begin{aligned}
C_{S} & =\text { concentration at surface of sphere, } \\
C_{\infty} & =\text { concentration far from sphere, } \\
D & =\text { diffusivity of nuclei, } \\
r & =\text { radius of sphere, } \\
r_{\infty} & =\text { distance at which } C=C_{\infty} .
\end{aligned}
$$

For the attachment process $c_{s}=0$. Also, if $r_{\infty}$ is taken as large compared to $r$, and $C_{\infty}$ is taken as the bulk average concentration of nuclei, Equation (24) may be simplified to 
Equation (24a) was summed over all sodium aerosol particles to obtain the total uptake rate. When this uptake rate was divided by the number of nuclei present, an attachment constant, $k$, was found to be defined by

$$
K_{A}=\frac{12 D C_{A} d_{10}}{\rho d_{30}^{3}}
$$

where $K_{A}=$ attachment constant for nuclei to sodium aerosol, $\mathrm{sec}^{-1}$,

$D=$ diffusivity of nuclei particles, $\mathrm{cm}^{2} / \mathrm{sec}$,

$\mathrm{C}_{\mathrm{A}}=$ aerosol mass concentration, $\mathrm{g} / \mathrm{cm}^{3}$,

$d_{10}=$ number mean diameter for sodium aerosol, $\mathrm{cm}$,

$\rho=$ density of sodium aerosol particles, $\mathrm{g} / \mathrm{cm}^{3}$,

$d_{30}=$ volume mean diameter of sodium particles, $\mathrm{cm}$.

The fraction of the nuclei which attach to sodium particles is:

$$
\text { Fraction Attached }=1-\exp \left(-K_{A} t\right)
$$

where $t=$ time for attachment.

The diffusivity used in Equation (25) was calculated for the mass median particle size. Therefore, Equation (26) was assumed to apply to aerosol mass. 


\section{B. ASSESSMENT OF APPROXIMATIONS IN MODEL}

The models used to compute the size and degree of attachment of condensible contaminants contain a number of simplifying assumptions. In retrospect, all of the assumptions appear to be reasonable, and we expect no gross errors in the predictions.

Most of the approximations which have been made would cause our models to under-predict the degree to which the nuclei would become attached to sodium aerosol particles. Since the sodium aerosol particles are more efficiently removed than the freshly formed aerosol, the approximations would cause predictions to err on the conservative side.

Approximations in the models are expected to introduce less uncertainty into the predictions than will be caused by uncertainty in the input parameters. Uncertainties caused by variations of input parameters are illustrated later in this report in the section on parametric analysis. 


\section{AEROSOL CAPTURE IN SCRUBBER COMPONENTS}

\section{A. QUENCH SPRAY CHAMBER}

\section{Modeling Approach}

Removal of aerosol particles in the quench chamber was attributed to capture by falling drops. Key simplifying assumptions were:

- Gas flow rate was computed using an average temperature, and assuming the pressure was one atmosphere.

- Effects of water vapor condensation and evaporation on particle capture were neglected.

- Particle washout was computed from a model in which airborne concentration was uniform, and equal to the outlet concentration.

- Settling and deposition of aerosol particles on vessel surfaces were ignored.

- Spray performance was computed using an average drop size.

- Drops fall at terminal velocity.

- Spray acted as an assemblage of drops, and capture could be expressed in terms of a drop collection efficiency.

- Electrostatic and thermophoretic forces were neglected.

From these assumptions the fraction of an aerosol which would penetrate the quench chamber is found to be

$$
P=\frac{1}{1+\frac{3}{2}\left[\frac{L}{G}\right]\left[\frac{h}{d}\right] E}
$$

where $P$ = fractional aerosol penetration,

$$
\begin{aligned}
& L=\text { liquid spray flow rate, } \\
& G=\text { gas flow rate, }
\end{aligned}
$$




$$
\begin{aligned}
& h=\text { drop fall height, } \\
& d=\text { drop diameter, } \\
& E=\text { drop collection efficiency. }
\end{aligned}
$$

The quantities $L, G, h$, and $d$ are parameters of the quench chamber design, and were assigned baseline values. The fractional collection efficiency, $E$, varies strongly with particle size, and its value was predicted theoretically. Overall penetration was found by summing Equation (27) for particle size increments allowing $E$ to vary with particle size.

\section{Collection Mechanisms}

The dominant collection mechanisms in the quench chamber are interception, inertial impaction, and diffusion. Interception was computed for potential flow according to an expression due to Ranz and Wong ${ }^{(11)}$ :

$$
E_{R}=3 \frac{d p}{d_{d}}
$$

where $E_{R}=$ collection efficiency for interception,

$$
\begin{aligned}
& d_{p}=\text { particle diameter }, \\
& d_{d}=\text { drop diameter. }
\end{aligned}
$$

Inertial impaction is important for large particles which are able to cross stream lines and collide with falling drops. The impaction parameter, also called the Stokes number, which describes this process is defined by 


$$
s t k=\frac{\rho d_{p}^{2} U}{9 \mu d_{d}}
$$

$$
\begin{aligned}
& \text { Where stk } \\
& \qquad \begin{aligned}
\rho & =\text { Stokes number }, \\
U & =\text { relative velocity between gas and falling drop, } \\
\mu & =\text { gas viscosity }
\end{aligned}
\end{aligned}
$$

The relative velocity, $U$, was equated to the terminal drop settling velocity. The impaction efficiency was computed from Langmuir's equation(12) for potential flow:

$$
E_{I}=\frac{s t k^{2}}{(s t k+0.5)^{2}}
$$

Capture by Brownian diffusion was related to the Reynolds number and Peclet number using an approximation $(13)$ to a boundary layer equation developed by Suneja (14). The capture efficiency due to diffusion was calculated according to

$$
E_{B D}=3.2 \operatorname{Re}^{1 / 6} \mathrm{Pe}^{-2 / 3}
$$

where $\operatorname{Re}=$ drop Reynolds number,

$$
\text { Pe }=\text { Peclet number } \text {. }
$$


The Peclet number is defined as

$$
P e=\frac{d_{d} U}{D}
$$

$$
\text { where } \begin{aligned}
d_{d} & =\text { drop diameter, } \\
U & =\text { drop falling velocity, } \\
D & =\text { particle diffusivity. }
\end{aligned}
$$

The overall E used in Equation (27) was the sum of the E values for three mechanisms:

$$
E=E_{R}+E_{I}+E_{B D}
$$

\section{B. EDUCTOR VENTURI}

1. Modeling Approach

The eductor scrubber envisioned in the present study was modeled as a spray scrubber. The collection efficiency was computed using Equation (27), accounting for capture by impaction and interception.

\section{Design Parameter Values}

Liquid flow rate, drop size, and drop path length are venturi scrubber parameters which must be known. A first estimate of reasonable values for these parameters led to the following:

$$
\begin{aligned}
& \text { 1iquid/gas }=0.00668(50 \mathrm{gpm} / 1000 \mathrm{SCFM}) \\
& \text { drop diameter }=1500 \text { micrometers } \\
& \text { scrubbing path length }=1.53 \mathrm{~m}(5 \mathrm{ft})
\end{aligned}
$$

It is recognized that these parameters are not optimum in terms of 
realistically describing the aerosol washout capability of the eductor venturi. This lack of preciseness has little impact on the overall performance of the air cleaning system. From results described later in this report, the venturi removes little aerosol material because the large, easily removed particles are removed upstream in the quench chamber. Small particles which penetrate the quench spray also penetrate the eductor venturi scrubber.

\section{FIBROUS BED SCRUBBER}

\section{Model ing Approach}

The fibrous bed scrubber was modeled as a bed of fibers aligned perpendicularly to the air flow direction. From a material balance on a differential element of bed length one can compute the change in particle concentration as

$$
\frac{d c}{c}=-k d x
$$

$$
\text { where } \begin{aligned}
c & =\text { particle concentration at } x, \\
k & =\text { removal constant } \\
x & =\text { distance measured in air flow direction. }
\end{aligned}
$$

Integrating Equation (34) from $x=0$ to $x=L$, the aerosol penetration is found to be

$$
\begin{aligned}
& \text { penetration }=\frac{c}{c_{0}}=\exp (-k L) \\
& \text { where } k=\frac{4(1-\varepsilon) E_{f}}{d_{f} \varepsilon}
\end{aligned}
$$




$$
\begin{aligned}
L & =\text { length of bed in air flow direction, } \\
\varepsilon & =\text { void volume fraction of bed, } \\
E_{f} & =\text { single fiber collection efficiency, } \\
d_{f} & =\text { diameter of fibers. }
\end{aligned}
$$

Equation (35) was used to predict the aerosol removal efficiency of the fibrous scrubber. Fiber diameter was taken as a constant for the whole bed, and the presence of collected mist particles was neglected.

\section{Aerosol Capture Mechanisms}

Dominant capture mechanisms in the fiber bed are diffusion, interception, and impaction. Diffusion was accounted for using an equation based on the analogy between heat transfer and mass transfer ${ }^{(15)}$ :

$$
E_{D}=\frac{1}{P e}+1.727 \frac{R^{1 / 6}}{P e^{2 / 3}}
$$

where $E_{D}=$ fiber collection efficiency due to diffusion,

$$
\begin{aligned}
P e & =\text { Peclet number }=\frac{d_{f} U_{o}}{D}, \\
R e & =\text { Reynolds number }=\frac{d_{f} U_{o} \rho}{\mu}, \\
d_{f} & =\text { fiber diameter }, \\
U_{0} & =\text { gas velocity far from fiber, } \\
D & =\text { particle diffusivity, } \\
\rho & =\text { gas density, } \\
\mu & =\text { gas viscosity. }
\end{aligned}
$$

Interception and impaction were accounted for by using numerical computations of particle capture tabulated by Davies ${ }^{(16)}$. The single fiber collection efficiencies were computed using the so-called "Spielman-Goren" 
flow field by "Dawson". The data presented in Table X of reference (16) were plotted to facilitate interpolation for specific Stokes numbers, and particle diameter to fiber diameter ratios. The total single fiber collection efficiency was taken to be the sum of that for the three mechanisms.

\section{Penetration/Size Curve}

The particle removal efficiency curve predicted for base case parameters is shown in Figure 15 to illustrate the results obtained for the fibrous filter. The following parameters were used for the calculation:

$$
\begin{aligned}
& \text { fiber diameter }=20 \text { micrometers } \\
& \text { gas superficial velocity }=0.0764 \mathrm{~m} / \mathrm{s}(15 \mathrm{ft} / \mathrm{min}) \\
& \text { gas viscosity }=1.9 \times 10^{-4} \text { poise } \\
& \text { bed length }=0.0762 \mathrm{~m}(3 \text { inches }) \\
& \text { bed porosity }=0.8 .
\end{aligned}
$$

As shown by the curve of Figure 15, the fiber bed is predicted to have a high removal efficiency for all particle sizes. The peak penetration is 0.024 and occurs at a particle diameter of 0.4 micrometer.

For particles smaller than 0.06 microns and those larger than 1.1 microns, the penetration is predicted to be smaller than $10^{-6}$. As noted in Figure 15, a cut-off limit of $10^{-6}$ was used to account for bypass leakage and liquid entrainment.

Small particles are efficiently trapped by diffusion and large particles are trapped by interception and impaction in the fiber bed. Only those of intermediate size show an appreciable penetration. 


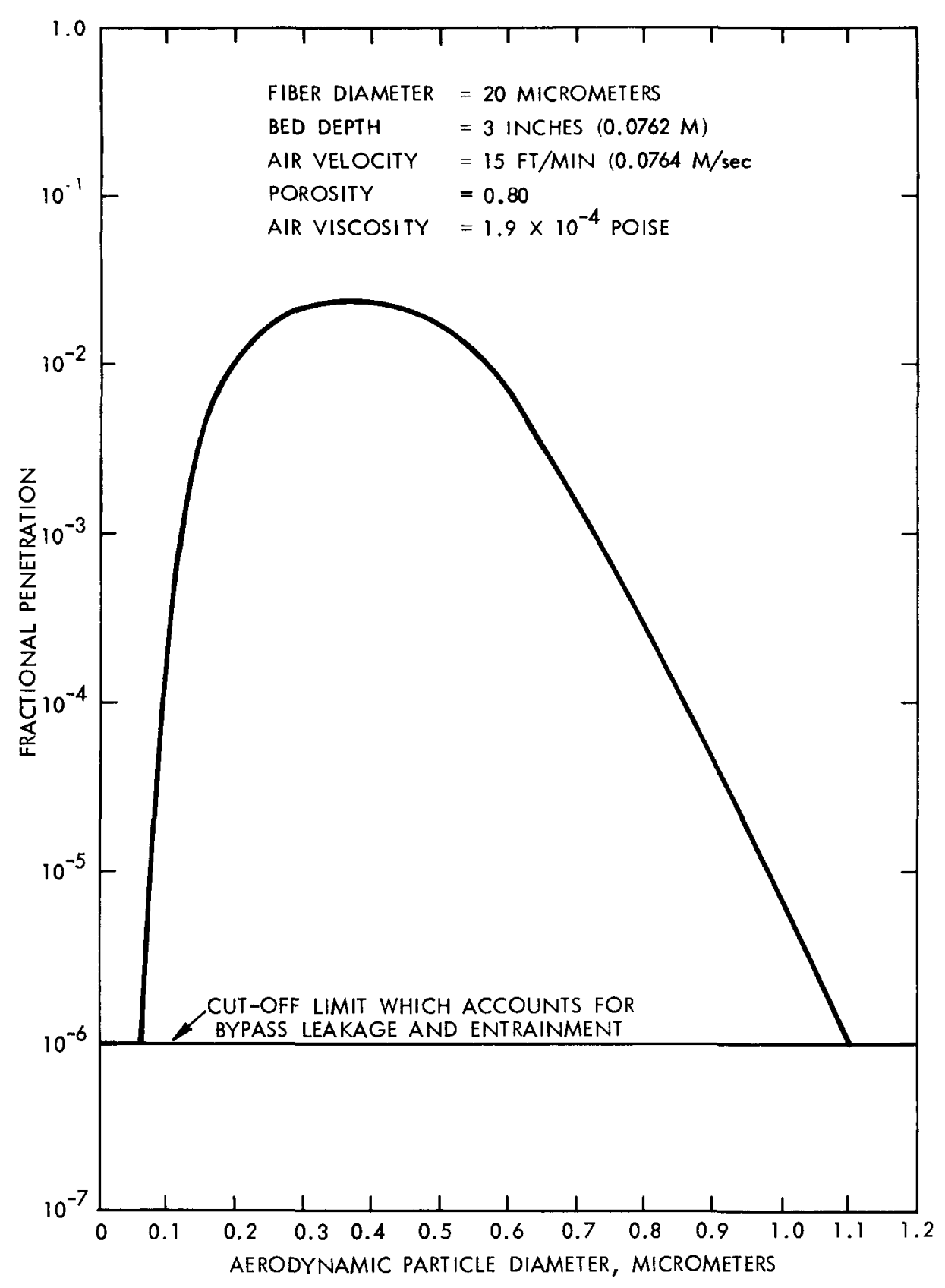

HEDL 7805-009.20

FIGURE 15. Particle Penetration Through Fiber Bed. 


\section{PARAMETRIC EVALUATIONS}

The most important variables in the air cleaning system were treated as parameters to show how the removal efficiency would vary as each variable departed from an assigned baseline value. Results of the parametric analysis are useful to:

- Identify the most important variables.

- Establish the range over which one could reasonably expect the removal efficiency to vary.

- Aid the final design of the air cleaning system.

- Aid the design of air cleaning experiments.

\section{A. VARIABLES CONSIDERED}

The variables which are significant in the nucleation and capture models used in this study are described in the following paragraphs. A brief discussion is provided to highlight the physical importance of each variable.

\section{Properties of Volatile Material}

Properties of the condensible vapor which would affect the size and degree of attachment of freshly nucleated particles are the following.

\section{a. Mass Concentration of Vapor}

The mass concentration of vapor present in the containment vessel determines the maximum mass of fresh nuclei which can be formed in the quench chamber. The mass concentration of fresh aerosol determines how large the particles are, and thereby the degree of attachment to sodium aerosol. This variable was treated as a parameter, with the base value being chosen to reflect a hypothetical situation where the containment 
vessel atmosphere was saturated with $\mathrm{NaI}$ at $700^{\circ} \mathrm{K}\left(800^{\circ} \mathrm{F}\right)$. At $700^{\circ} \mathrm{K}$ $\left(800^{\circ} \mathrm{F}\right)$, about $1 \%$ of core iodine would saturate the containment atmosphere if present as $\mathrm{NaI}$ vapor.

The vapor pressure of $\mathrm{NaI}$ was taken fron the measurements of Cogin and Kimbal1 (7), whose data are plotted in Figure 16. As indicated in the figure, data cover a temperature range from $735.4^{\circ} \mathrm{K}\left(866^{\circ} \mathrm{F}\right)$ to $902.5^{\circ} \mathrm{K}$ $\left(1165^{\circ} \mathrm{F}\right)$. Extrapolation of the vapor pressure curve was necessary to obtain values for the base case where saturation at $700^{\circ} \mathrm{K}\left(800^{\circ} \mathrm{F}\right)$ was assumed.

\section{b. Slope of Vapor Pressure Curve}

The slope of the vapor pressure curve influences how rapidly supersaturation develops as temperature drops. In Equation (15), the variable $A$ is a measure of the slope of the vapor pressure curve. From thermodynamics, it is known that this slope is proportional to the latent heat of vaporization for the chemical specie of interest. This parameter is not expected to be very important because almost all of the condensible mass would be condensed out at the low temperatures reached in the quench chamber. Therefore this variable was kept constant at the value which applies to $\mathrm{NaI}$.

\section{c. Critical Supersaturation Level}

As discussed earlier in this report, homogeneous nucleation occurs at an appreciable rate only after a critical level of supersaturation has been reached. This critical level can be estimated from nucleation theory. This variable would be quite important if the condensible material were to undergo small temperature changes in the quench chamber. However, calculations showed that for $\mathrm{NaI}$, the hot containment gases were supersaturated by factors of about $10^{8}$ with respect to the gas exiting from the quench chamber. Therefore the point at which nucleation begins should not play a major role in the final particle size formed. This 


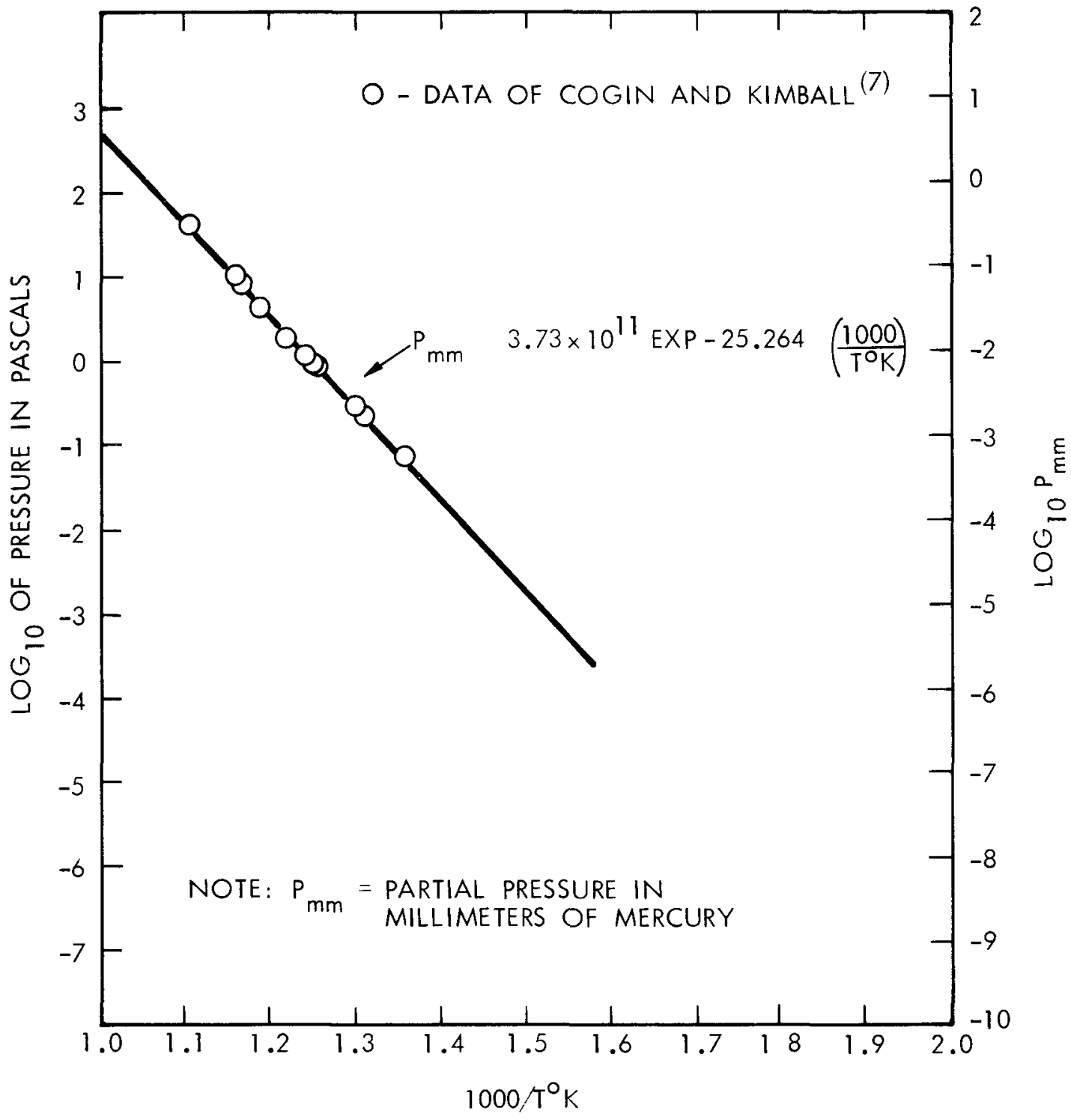

HEDL 7805-009.1a

FIGURE 16. Vapor Pressure of Sodium Iodide. 
variable was not treated as a parameter. Rather, it was assumed that the critical saturation ratio was in the range of 4 to 50, as shown in Figure 13, which translates to a $K / R$ value of about 0.1 .

\section{d. Diffusivity of Vapor}

Vapor diffusivity affects the size of nucleated particles because for higher diffusivities, fewer nuclei are required to limit supersaturation levels on a local scale. Diffusivity affects the value of $K$, as described in Equation (16).

Gas phase diffusivity is related to temperature and vapor properties by the following dimensional formula ${ }^{(17)}$ :

$$
D=0.0043 \frac{T^{3 / 2}}{P\left[V_{A}^{1 / 3}+V_{B}^{1 / 3}\right]_{2}} \sqrt{\frac{1}{M_{A}}+\frac{1}{M_{B}}}
$$

where $D=$ diffusivity of mixture of gases $A$ and $B, \mathrm{~cm}^{2} / \mathrm{sec}$,

$$
\begin{aligned}
T & =\text { absolute temperature, }{ }^{\circ} \mathrm{K}, \\
P & =\text { absolute pressure, atmospheres, } \\
V_{A} & =\text { molecular volume of specie } A, \mathrm{~cm}^{3} / \mathrm{g} \text {-mole, } \\
V_{B} & =\text { molecular volume of specie } B, \mathrm{~cm}^{3} / \mathrm{g} \text {-mole, } \\
M_{A} & =\text { molecular weight of specie } A, \\
M_{B} & =\text { molecular weight of specie } B .
\end{aligned}
$$

From Equation (37), gas phase diffusivity varies with the $3 / 2$ power of temperature, and as the inverse square root of molecular weight. Because molecular weights of condensible volatile species would not be too different we used Equation (37) evaluated for $\mathrm{NaI}$ in air to predict diffusivity. Any deviations from the values for $\mathrm{NaI}$ in air are expected to have only minor influences on the properties of the freshly nucleated aerosol. 


\section{e. Density of Solid Form of Condensible Vapor}

The density of solid particles formed by condensing vapor plays a minor role in determining the aerodynamic behavior of the freshly nucleated aerosol. Because the densities of solid fission products do not vary widely, we assumed the primary particle density to be that for NaI $\left(3.68 \mathrm{~g} / \mathrm{cm}^{3}\right)$.

\section{Properties of Sodium Aerosol}

\section{a. Mass Concentration of Sodium Aerosol}

Preliminary evaluations of containment system design ${ }^{(18)}$ have provided information on the concentration and properties of sodium aerosol which might be airborne in the containment atmosphere for the low probability accident situations which would employ the EACS. The analyses completed showed that a mass concentration of $50 \mathrm{~g} / \mathrm{m}^{3}$ would exist for most of the operational time period. This variable is important because it affects the size of sodium aerosol particles, and the degree of attachment of freshly nucleated particles. Both of these factors strongly influence the removal efficiency in the EACS. Therefore, mass concentration of sodium aerosol was considered an independent variable.

\section{b. Particle Size of Sodium Aerosol}

Particle size is a key parameter in determining the removal efficiency of the scrubber EACS. Particle size is obviously dependent on the generation and agglomeration processes which take place in the containment vessel. Therefore, in principle, one should obtain the best available predictions of particle size for each case analyzed. As a simplification in the present study we used existing computer analyses based on the HAA-3 code ${ }^{(10)}$ to correlate particle size to mass concentration. Both the mass median diameter and standard deviation (assuming log-normal distribution) are plotted in Figure 17 as functions of airborne 


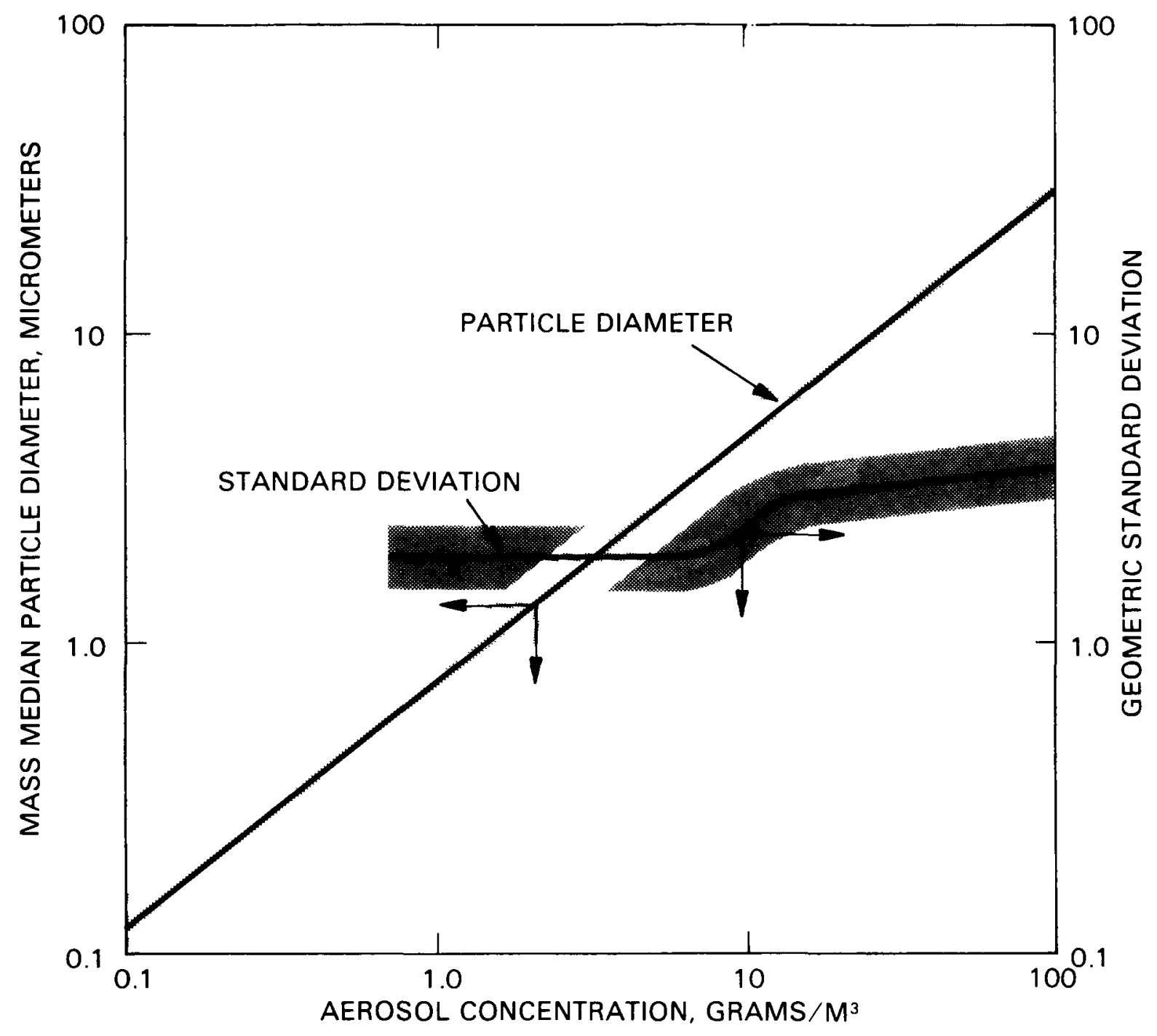

HEDL 7810-060.3

FIGURE 17. Correlation of Particle Size with Aerosol Concentration in Containment Atmosphere. 
mass concentration. The lines drawn through the shaded areas in Figure 17 were used to determine the size of sodium compound aerosols which entered the EACS. These correlations resulted from an HAA-3 run in which differences in source rate led to varying airborne concentrations. Density modification factor, $\alpha$, was assigned a value of 0.10 and material density was taken as 2.13 in the computer runs used to generate the curves of Figure 17 .

\section{c. Density of Sodium Aerosol Particles}

Sodium released to the containment building was assumed to react with oxygen and water vapor to form $\mathrm{NaOH}$. The water vapor is the normal humidity plus water released from heated concrete $(19)$. Sodium aerosol density was based on a density modification factor of 0.10 and a material density of $2.13 \mathrm{~g} / \mathrm{cm}^{3}$ which applies to $\mathrm{NaOH}^{(20)}$. Agglomerate particle density was thus assumed to be:

$$
0.10(2.13)=0.213 \mathrm{~g} / \mathrm{cm}^{3}
$$

\section{Therma 1 Conditions in Quench Chamber}

\section{a. Inlet Gas Temperature}

Temperature of gas entering the quench chamber affects several aspects of scrubber performance. These include:

- diffusivity of condensible vapor

- heat load to quench spray

- vapor pressure of a specific condensible contaminant.

Accident analyses which have been carried out to determine thermal margins show that the temperature of the containment atmosphere varies with time and other factors downwards from $540^{\circ} \mathrm{C}\left(1000^{\circ} \mathrm{F}\right)$. For the present study 
we assumed that the inlet temperature was $427^{\circ} \mathrm{C}\left(800^{\circ} \mathrm{F}\right)$. Since temperature is not a critical variable, it was not treated as a parameter.

\section{b. Inlet Water Temperature}

The primary effect of inlet water temperature is to fix the temperature of gas exiting from the quench chamber. Inlet water temperature would likely fall within the range of $300^{\circ} \mathrm{K}$ to $322^{\circ} \mathrm{K}\left(80^{\circ} \mathrm{F}\right.$ to $\left.120^{\circ} \mathrm{F}\right)$, depending on its source and the type of coolers used. Because temperature does not strongly affect particle behavior, an inlet temperature of $311^{\circ} \mathrm{K}$ $\left(100^{\circ} \mathrm{F}\right)$, was used for all parametric evaluations.

\section{c. Water Spray Rate and Drop Size}

Water spray rate would be selected to achieve the desired degree of cooling. It would also affect the fractional removal of aerosol particles. The performance of a spray cooler is importantly dependent on the drop size as well as spray rate, so both variables must be specified. Our approach was to first specify a drop diameter of 1000 micrometers, and then estimate spray rates which would be required to obtain a close approach between incoming water and outlet gas. The specified drop size can be produced by hollow cone nozzles with large openings and operated at modest pressure drops. Preliminary heat transfer calculations showed that a spray rate of 0.00334 on a dimensionless basis (25 gpm/CFM) was sufficient. A spray rate of $0.0316 \mathrm{~m}^{3} / \mathrm{s}$ (500 gpm) was selected as a base value, and kept constant for all cases analyzed.

\section{d. Spray Fall Height}

Spray fall height is important because it determines the amount of heat transfer and particle capture which can be accomplished by falling drops. For the present study we picked $6.0 \mathrm{~m}(20 \mathrm{ft})$ as a reasonable baseline value, and also analyzed aerosol behavior for fall heights larger and smaller than this value by a factor of 2 . 


\section{Time for Attachment of Nuclei to Sodium Aerosol}

The fractional attachment of freshly formed nuclei to sodium aerosol depends on the attachment constant and time, as shown in Equation (26). We estimated the time for attachment on the basis of plug flow through the upper half of the quench chamber. The quench chamber volume was kept constant, so attachment time varied only with gas flow rate.

\section{Removal Efficiency of Scrubber Components}

Several quench tank design parameters which would affect particle removal efficiency have already been discussed. These are drop size, spray fall height, and spray flow rate. Other design parameters which affect particle scrubbing efficiency are described in the following.

\section{a. Eductor Venturi Spray Characteristics}

The eductor venturi scrubber, pictured schematically in Figure 5, removes particles chiefly by spray impaction. Therefore, spray flow rate, drop size, and path length would all affect the removal efficiency. We used only one value for each of these parameters. Numerical values which are thought be be of reasonable, intermediate magnitude are:

$$
\begin{aligned}
& \text { spray flow rate }=0.0632 \mathrm{~m}^{3} / \mathrm{s}(1000 \mathrm{gal} / \mathrm{min}) \\
& \text { spray drop diameter }=1500 \text { micrometers } \\
& \text { length of drop path }=1.53 \mathrm{~m}(5 \mathrm{ft})
\end{aligned}
$$

In the present application the eductor will achieve low removal efficiencies because it is downstream from the quench chamber. The easily removed large aerosol particles will already have been removed in the quench chamber so the venturi will be scrubbing the smaller, more difficult to remove particles. Because the venturi scrubber will show low removal efficiencies, we did not treat its design variables as parameters. 


\section{b. Diameter of Fibers in Fibrous Scrubber}

The removal efficiency of the fibrous scrubber is sensitively dependent upon fiber diameter. Not only does the target area increase inversely with fiber diameter (Equation 35), but the target efficiency also increases inversely with fiber size.

A baseline fiber diameter of 20 micrometers was assigned on the basis of measurements on a fibrous scrubber of the same design reported in reference (2). In order to show how removal efficiency varied with fiber size, this parameter was varied from 10 micrometers to 40 micrometers.

\section{c. Thickness of Fibrous Bed Scrubber}

Equation (35) shows that for a constant target efficiency, the fractional penetration decreases exponentially with bed length, L. A baseline bed thickness of $0.0762 \mathrm{~m}$ ( 3 inches) was assigned on the basis of manufacturers specifications for a so-called "high efficiency" design. Bed thickness was varied from $0.0254 \mathrm{~m}$ ( 1 inch) to $0.152 \mathrm{~m}$ ( 6 inches) to show how overal1 aerosol penetration varies with bed thickness.

\section{d. Gas Flow Rate}

The containment purge rate is an operational variable which would be controlled to limit the hydrogen concentration in the containment atmosphere. The maximum design flow rate is 20,000 SCFM, a flow rate which would occur soon after the purge/venting procedure was begun. After a few days, the flow rate would have decreased to 1000 SCFM or less. The baseline flow rate of 20,000 SCFM was selected to mirror the maximum value noted above. Flow rate was varied from 5000 SCFM to 25,000 SCFM to illustrate how removal efficiency varied with gas flow rate. 


\section{B. AEROSOL REMOVAL PREDICTED FOR THE BASE CASE}

\section{Homogeneous Nucleation Versus Heterogeneous Nucleation}

For the base case, sodium compound aerosol concentration was $50 \mathrm{~g} / \mathrm{m}^{3}$, a very high aerosol concentration. The degree to which $\mathrm{NaI}$ would condense onto sodium aerosol particles was estimated from $K / R$ for sodium aerosol. The value of $K$ estimated from Equation (17) was 900 , leading to a $K / R$ of $0.0013^{\circ} \mathrm{K}^{-1}$. This value is too small by a factor of 0.01 to prevent homogeneous nucleation, and therefore homogeneous nucleation would dominate. Although a small percentage of $\mathrm{NaI}$ would be expected to condense as vapor onto the sodium aerosol, this was neglected in assessing $\mathrm{NaI}$ removal in the air cleaning components. Neglecting vapor deposition onto sodium aerosol particles is conservative because sodium aerosol is more efficiently removed in the air cleaning system than $\mathrm{NaI}$ aerosol.

\section{Sizes of Aerosol Particles}

Two distinct aerosol particle populations will enter the scrubber system. The sodium aerosol mass median diameter and standard deviation are 17 micrometers and 3.4 respectively. The aerodynamic mass median diameter is 12.4 micrometers. The distribution of sodium aerosol sizes is shown in Figure 18.

The diameter of agglomerated $\mathrm{NaI}$ particles was predicted to be 0.05 micrometers, mass median diameter. Since the density of the agglomerated particles of $\mathrm{NaI}$ were predicted to be very close to unity, the predicted aerodynamic diameter was 0.05 micrometers. The size distribution for $\mathrm{NaI}$ particles is presented in Figure 18, using an assumed standard deviation of 2 .

Capture of aerosol populations was computed by breaking each distribution into a number of increments. Sixteen increments were used for the sodium aerosol and eight were used for the $\mathrm{NaI}$ aerosol. 


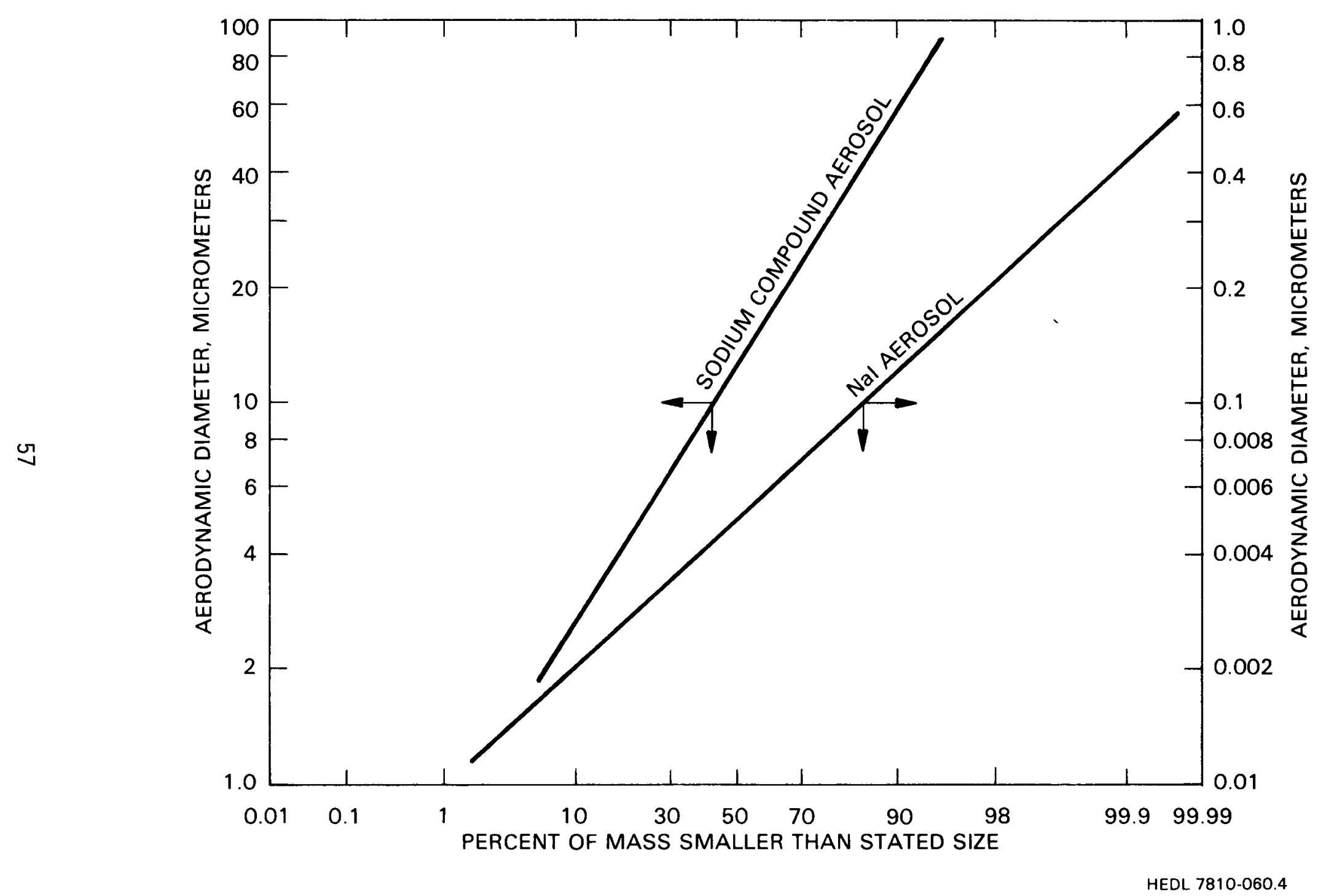

FIGURE 18. Size of Particles Populations for Base Case. 


\section{Fraction of $\mathrm{NaI}$ Aerosol Attached to Sodium Aerosol}

The degree to which agglomerated $\mathrm{NaI}$ aerosol coagglomerated with sodium aerosol was computed using Equation (26). Time for attachment was estimated to be $8.1 \mathrm{sec}$, and the attachment constant was estimated to be $0.0228 \mathrm{sec}^{-1}$. Using these numbers, 84 percent of the $\mathrm{NaI}$ aerosol was found to be attached to sodium compound particles, and 16 percent remained as a separate aerosol population.

\section{Aerosol Removal in Scrubber}

The removal efficiency of the scrubber components for sodium aerosol and the $\mathrm{NaI}$ aerosol was computed using the models previously described. Results are summarized in Table 1.

TABLE 1.

AEROSOL PENETRATION THROUGH SCRUBBER COMPONENTS FOR THE BASE CASE

\section{Fractional Penetration}

\begin{tabular}{|c|c|c|c|c|}
\hline Aerosol Type & $\begin{array}{l}\text { Quench } \\
\text { Spray }\end{array}$ & $\begin{array}{l}\text { Eductor } \\
\text { Venturi }\end{array}$ & $\begin{array}{l}\text { Fibrous } \\
\text { Scrubber }\end{array}$ & $\begin{array}{l}\text { Overa } 11 \\
\text { System }\end{array}$ \\
\hline Sodium Compound & 0.126 & 0.549 & $2.34 \times 10^{-3}$ & $1.62 \times 10^{-4}$ \\
\hline $\begin{array}{c}\text { Volatile } \\
\text { Fission Product } \\
\text { (NaI) }\end{array}$ & 1.0 & 1.0 & $1.07 \times 10^{-3}$ & $1.07 \times 10^{-3}$ \\
\hline
\end{tabular}

As shown by the results presented in Table 1, the volatile fission product aerosol is removed to an appreciable extent only by the fibrous scrubber. However, since most of the fission product aerosol is attached to sodium aerosol particles, the fission product material is removed to a significant extent $(93.1 \%)$ in the quench spray and eductor venturi scrubber components. 
The overall penetration of fission product aerosol is penetration $=\left(1.62 \times 10^{-4}\right)(0.842)=\left(1.07 \times 10^{-3}\right)(0.158)=3.05 \times 10^{-4}$ which is only slightly higher than the penetration of sodium aerosol.

\section{RESULTS OF PARAMETRIC ANALYSIS}

\section{Effect of Gas Flow Rate}

Aerosol behavior in the scrubber system was calculated as a function of gas flow rate. The primary effect of gas flow rate changes are:

- Liquid/gas rate directly affects penetration of spray and eductor scrubber units as indicated in Equation (27).

- Fiber target efficiency for fibrous bed changes as indicated in Equation (36).

- Fractional attachment of freshly nucleated aerosol to sodium changes, as indicated by Equation (26).

- The size of freshly nucleated particles varies with gas residence time as indicated in Equation (22) and Equation (23).

The fractional penetration of freshly nucleated particles is plotted as a function of flow rate in Figure 19. Also shown is the penetration for sodium aerosol. As indicated, penetration increases with flow rate, until a maximum is reached. The maximum in the penetration curve occurs at the base case flow rate. It should be noted that the penetration of freshly formed aerosol is highly influenced by attachment to sodium aerosol particles. At the lower flow rates, where agglomeration times are greatest, the two curves merge.

\section{Effect of Sodium Aerosol Concentration}

The overall capture of freshly nucleated particles was computed for a wide range of concentrations of sodium aerosol. Sodium aerosol concentration 


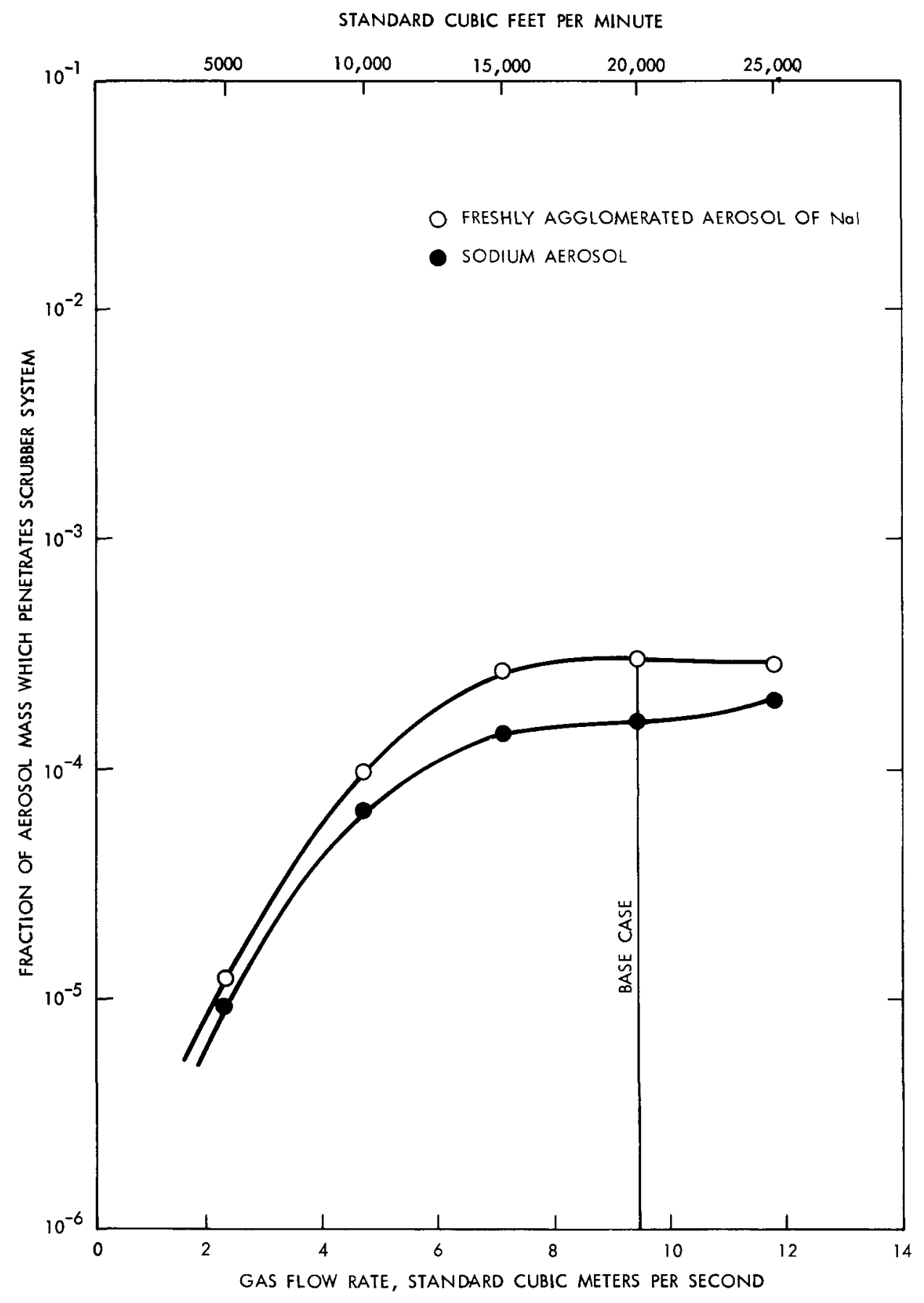

HEDL 7805-009. 19

FIGURE 19. Effect of Gas Flow Rate on the Penetration of Aerosols Through Scrubbing System. 
affects the removal efficiency because:

- Sodium aerosol particle size varies with concentration (Figure 17).

- Attachment of freshly nucleated particles to sodium particles varies with sodium aerosol concentration and particle size (Equation 25).

Overall penetration of freshly formed aerosol is shown in Figure 20 as a function of sodium aerosol concentration. Also shown is the penetration of sodium aerosol.

Penetration reaches a maximum of about 0.01 at a concentration of $0.4 \mathrm{~g} / \mathrm{m}^{3}$. At this concentration, the mass median particle diameter is about 0.4 micron, which corresponds to the peak in the penetration curve for the fibrous bed scrubber (Figure 15).

As indicated by the similarity in the behavior of sodium aerosol and $\mathrm{NaI}$ aerosol, most of the fresh aerosol is attached to sodium aerosol particles. One aspect which seems to be a paradox is that the degree of attachment is greatest for the smallest mass concentration. Although one would intuitively expect attachment to be greater for the highest aerosol concentration, the attachment constant is more affected by particle size than mass concentration. The size effect is simply one of particle number concentration. Particle number concentration computed from HAA-3 code cases, as shown in Figure 17, increases with decreasing mass concentration.

\section{Effect of Spray Fall Height in Quench Chamber}

Particle removal efficiency in the spray chamber increases as the fall height increases, as indicated in Equation (27) Intuitively, one would expect little influence on overall removal, because the eductor venturi and fiber bed would efficiently capture any easily-removed particles 


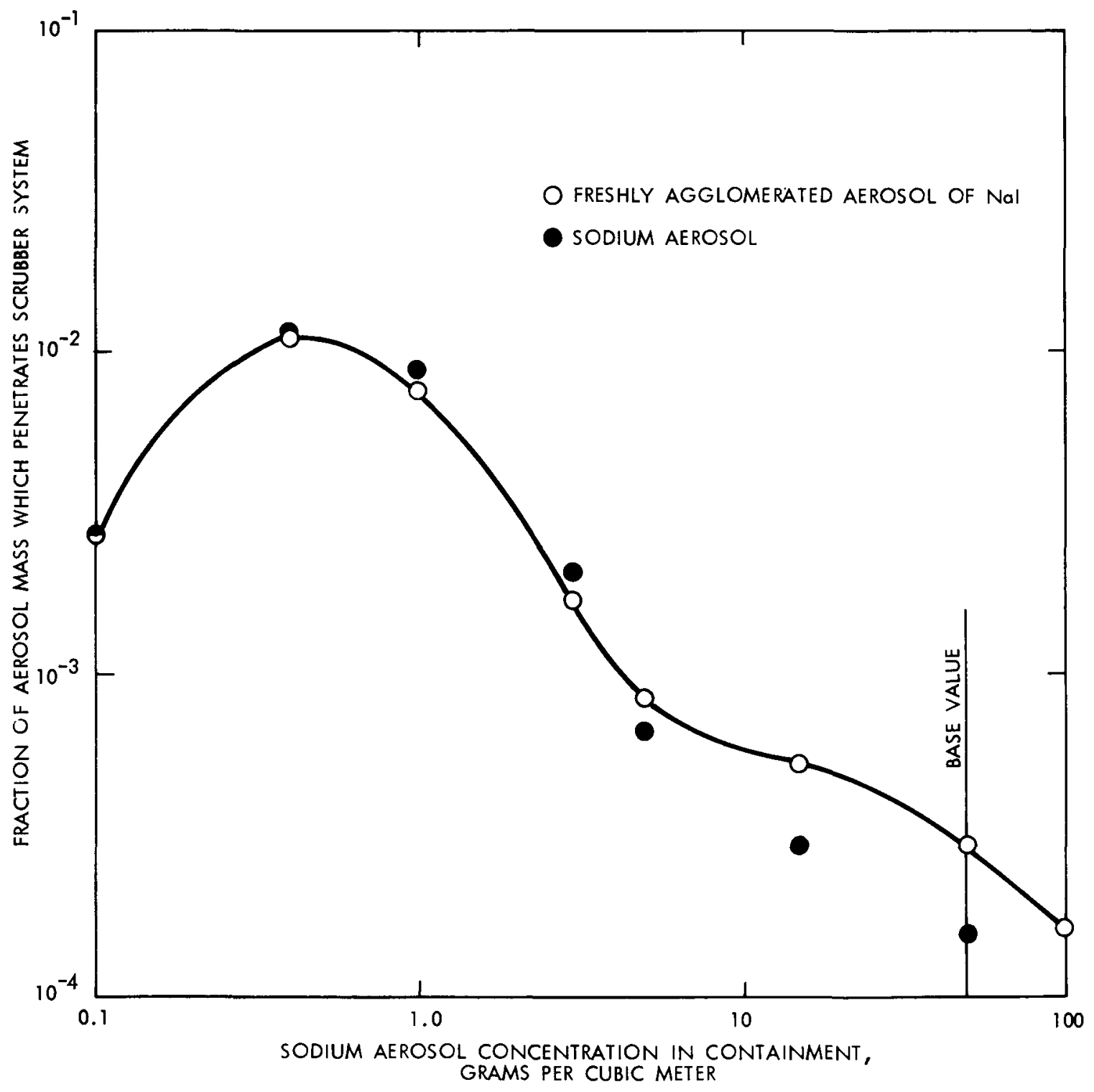

HEDL $7805-009.18$

FIGURE 20. Effect of Sodium Aerosol Concentration on Penetration of Aerosols Through Scrubbing System. 
which penetrate the quench chamber. This expectation is borne out by the data of Figure 21, where penetration is plotted versus chamber height.

When spray fall height was originally chosen as a parameter, it was conjectured that increased washout of sodium aerosol would decrease the calculated degree of attachment of the freshly agglomerated aerosol. However, decreased attachment was not observed to a significant extent. The reason is that the small particles, which are most effective for attachment, are not removed to an appreciable extent for any of the quench chamber heights considered.

\section{Effect of Thickness of Fibrous Bed Scrubber}

For a given particle size, Equation (35) indicates that penetration decreases exponentially with bed thickness. Since the fibrous scrubber is the most efficient component in the air cleaning train, changes in its efficiency would strongly influence the overall particle removal efficiency. This expectation is borne out by the data of Figure 22, where overall penetration is plotted as a function of bed thickness.

As indicated by the curves of Figure 22, penetration decreases rapidly with bed thickness. The pressure drop required to obtain air flow also increases with bed depth, and pressure drop limitations place a practical limit on bed thickness. The penetration at zero bed thickness extrapolates to about 0.02 . This is consistent with removal accomplished within the quench chamber and venturi scrubber.

\section{Effect of Fiber Diameter in Fibrous Bed Scrubber}

Fiber diameter affects both the fiber cross-sectional area exposed to gas flow and the target efficiency. Both of these factors vary inversely with fiber diameter, so removal efficiency would increase rapidly as fiber size decreased. Overall aerosol penetration is shown as a function 


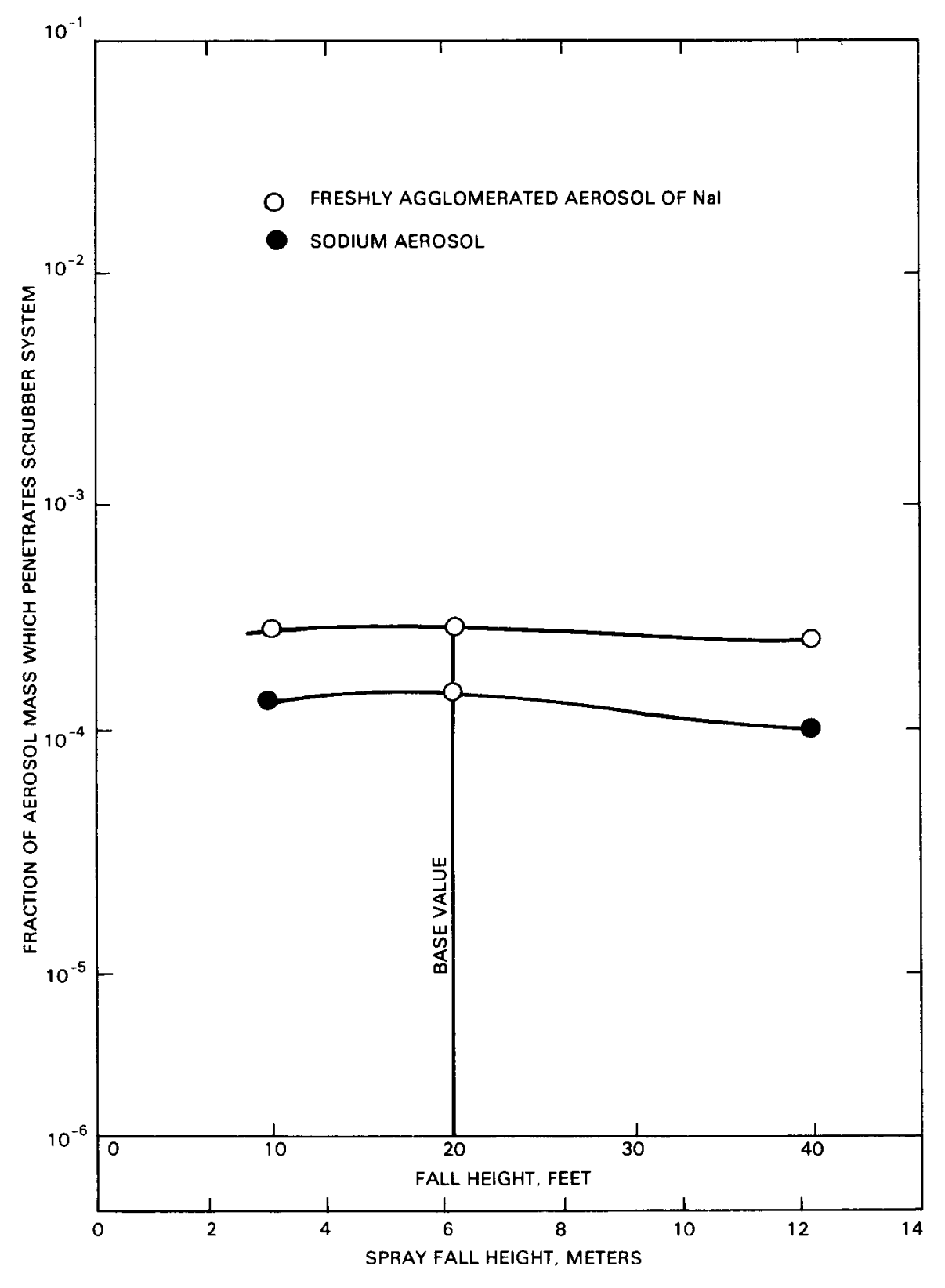

HEDL 7805-099.16

FIGURE 21. Effect of Quench Spray Fall Height on Aerosol Penetration. 


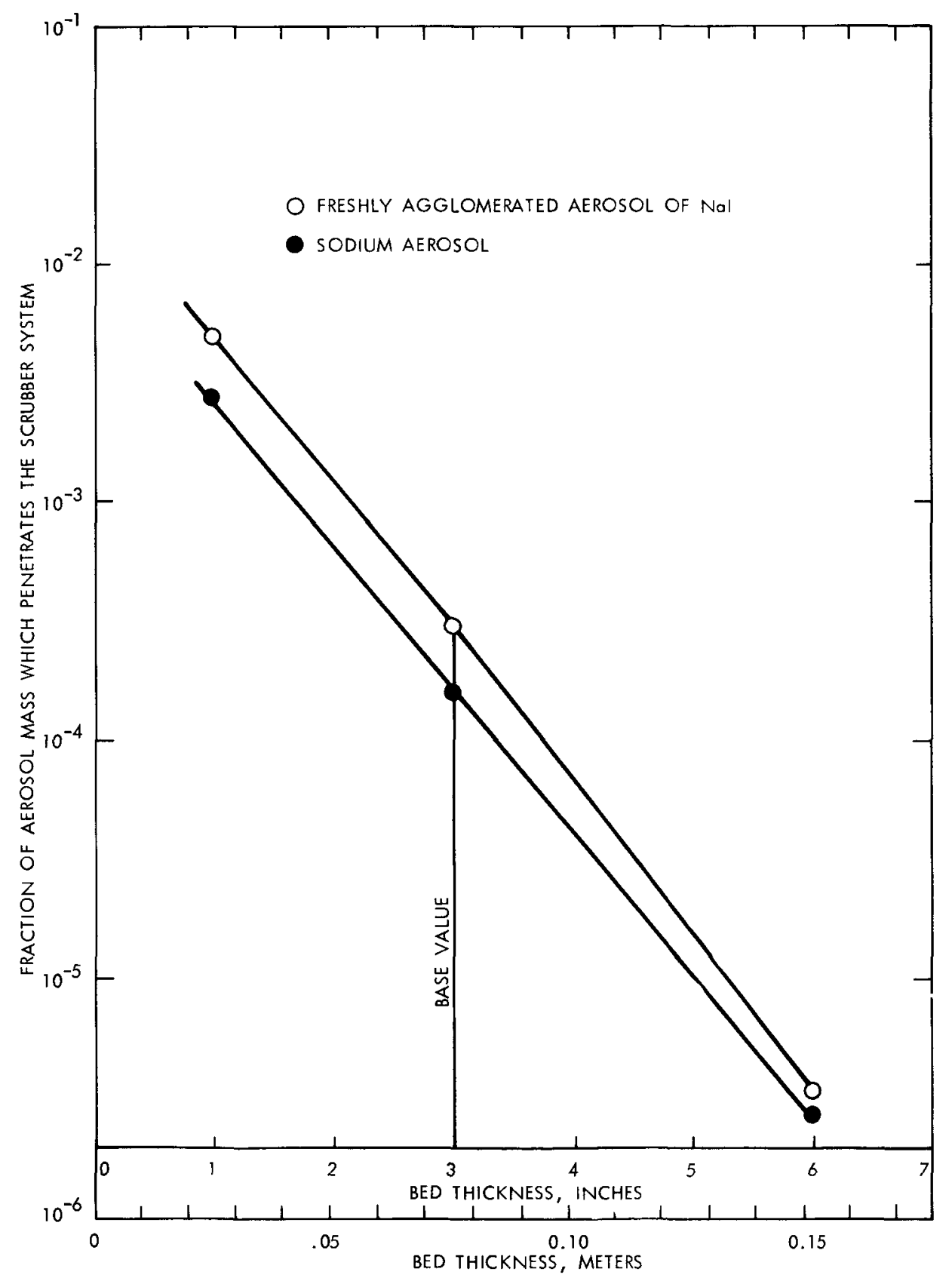

HEDL 7805-009.15

FIGURE 22. Effect of Thickness of Fibrous Bed Scrubber on Aerosol Penetration. 
of fiber diameter in Figure 23.

As expected, penetration is strongly influenced by fiber diameter. This strong dependency on fiber diameter indicates that the fibers in the scrubbing components actually tested should be measured. Predictions made with an erroneous fiber diameter could be misleading.

\section{Effect of Mass Concentration of Condensible Vapor}

The mass concentration of condensible vapor depends on the chemical form of fission products which are present and on the temperature of gas in the containment vessel. In our parametric analysis, we kept gas temperature constant and allowed just the airborne mass of condensible fission products to vary. While in reality both temperature and the chemical form of the volatile material would play a role, the effect of these two variables is thought to be minor in comparison to the mass itself.

Removal efficiency of fission product nuclei varies with mass concentration because the size of nuclei varies with vapor mass concentration. As the nuclei become larger, they tend to attach less efficiently to sodium aerosol particles, and also move toward the more penetration size range. Both effects cause the penetration to increase with volatile mass, as shown in Figure 24. The volatile mass is presented in terms of a mass ratio: unity corresponds to $\mathrm{NaI}$ saturated at $700^{\circ} \mathrm{K}\left(800^{\circ} \mathrm{F}\right)$, and amounts to $2.91 \times 10^{-4} \mathrm{~g} / \mathrm{m}^{3}$. Mass concentrations presented in Figure 24 range from $2.91 \times 10^{-5} \mathrm{~g} / \mathrm{m}^{3}$ to $2.91 \times 10^{-2} \mathrm{~g} / \mathrm{m}^{3}$.

As shown by the curves in Figure 24, penetration increased from $1.6 \times 10^{-4}$ at low mass concentration to $7 \times 10^{-3}$ at the highest mass concentration. A maximum penetration of about $1 \times 10^{-2}$ would be predicted for still higher masses. The maximum in penetration would correspond to freshly condensed aerosols having a mass median particle diameter of about 0.4 micron, the peak of the size-penetration curve for the fibrous scrubber (Figure 15). 


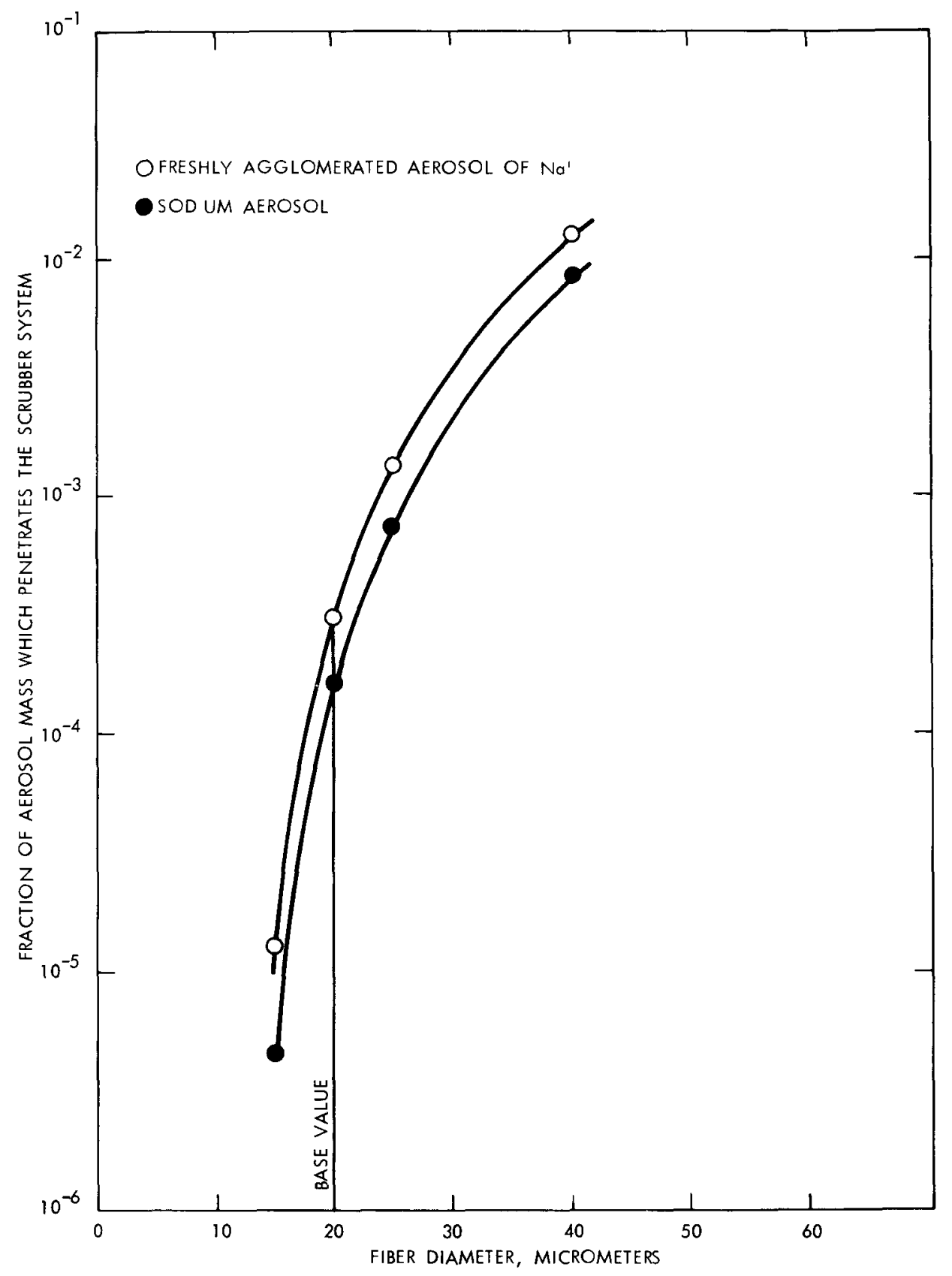

HEDL $7805-009.13$

FIGURE 23. Effect of Fiber Diameter in Fibrous Bed Scrubber on Aerosol Penetration. 


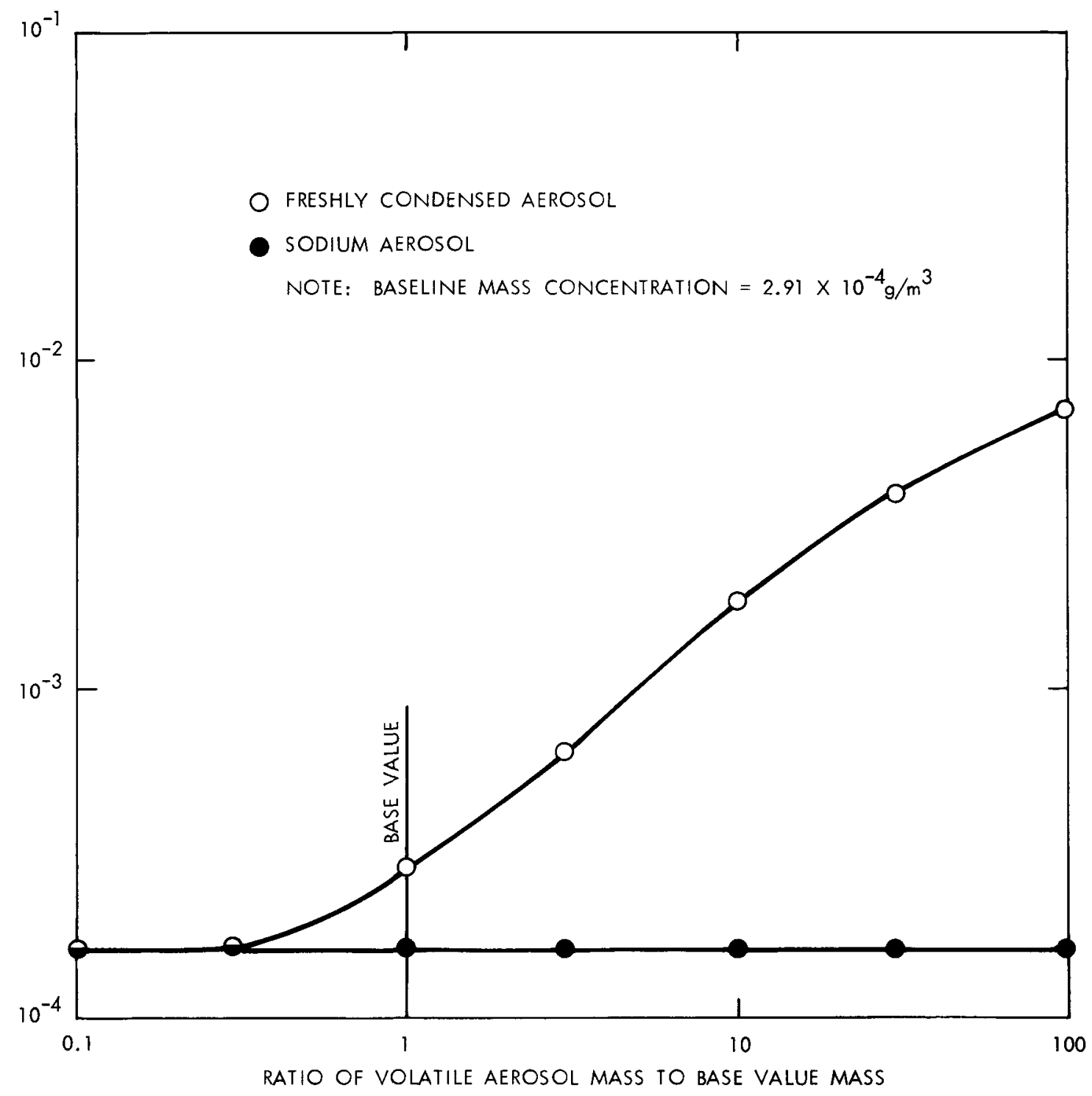

HEDL 7805-009.14

FIGURE 24. Effect of Volatile Mass on Aerosol Penetration. 
Fission product species which might be airborne as gases in a hot containment atmosphere include $\mathrm{NaI}, \mathrm{SeO}_{2}$, and $\mathrm{Sb}_{2} \mathrm{O}_{3}$. Masses of these materials and vapor pressures were reviewed to show the range required for the parametric variation of aerosol mass concentration.

Fission product masses in an equilibrium core were estimated from results presented by Bankert, et al. (21) for the FFTF. The masses presented by Bankert, et al. (21) were multiplied by 3 to account for the higher core power (1200 MWt) of the demonstration scale plant to which the air cleaning system applies. The estimated core inventories of the three fission product species are listed in Table?

\section{TABLE 2.}

\section{CORE INVENTORIES OF POTENTIALLY VOLATILE ELEMENTS}

$\begin{array}{cc}\text { Element } & \begin{array}{c}\text { Whole-Core } \\ \text { Inventory, Grams }\end{array} \\ \text { I } & 2673 \\ \text { Sb } & 360 \\ \text { Se } & 233\end{array}$

The upper bound to airborne mass concentration is determined by the vapor pressures of the chemical species involved. We computed the temperatures required to vaporize these elements in a $8.47 \times 10^{4} \mathrm{~m}^{3}$ gas volume, assuming ideal gas behavior. Vapor pressure of $\mathrm{NaI}$ was taken from the data of Cogin and Kimbal1 ${ }^{(7)}$. For $\mathrm{SeO}_{2}$ and $\mathrm{Sb}_{2} \mathrm{O}_{3}$, vapor pressures were obtained from the work of Behrens, et al. $(22,23)$. Temperatures required to vaporize specified fractions of the core inventory are listed in Table 3. 
TABLE 3.

TEMPERATURE REQUIRED TO VAPORIZE CORE INVENTORY OF FISSION PRODUCTS AIRBORNE AS NaI, $\mathrm{Sb}_{2} \mathrm{O}_{3}, A N D \mathrm{SeO}_{2}$.

\begin{tabular}{|c|c|c|c|c|c|}
\hline \multirow[b]{2}{*}{ Element } & \multirow{2}{*}{$\begin{array}{l}\text { Chemical } \\
\text { Form } \\
\end{array}$} & \multicolumn{4}{|c|}{ Temp ${ }^{\circ} \mathrm{C}$ For Stated Core Fraction Airborne } \\
\hline & & $x=10^{-3}$ & $x=10^{-2}$ & $x=10^{-1}$ & $x=1$ \\
\hline I & $\mathrm{NaI}$ & 392 & 435 & 487 & 542 \\
\hline $\mathrm{Sb}$ & $\mathrm{Sb}_{2} \mathrm{O}_{3}$ & 258 & 292 & 328 & 370 \\
\hline $\mathrm{Se}$ & $\mathrm{SeO}_{2}$ & 33 & 51 & 71 & 94 \\
\hline
\end{tabular}

As shown by the temperatures in Table $3, \mathrm{SeO}_{2}$ is the most volatile of the three species, and could be entirely gaseous at $94^{\circ} \mathrm{C}$. Sodium iodide is the least volatile. Containment atmosphere temperatures would have to be $542^{\circ} \mathrm{C}\left(1008^{\circ} \mathrm{F}\right)$ or higher to vaporize $\mathrm{NaI}$ equal in mass to the entire core inventory.

The walls of the containment vessel would be cooler than the gas phase, and this would lead to plateout of condensible fission products. Also, cooling in the wall boundary layer could cause nucleation of the condensible fission products in the boundary layer. Both of these effects would deplete the containment atmosphere of condensible fission products, and reduce the amount which could enter the air cleaning system. The effects of containment walls which are cooler than the gas temperature have been neglected in the present study.

The temperature of gas exiting from the quench chamber is expected to be lower than $49^{\circ} \mathrm{C}\left(120^{\circ} \mathrm{F}\right)$ and thus nearly all of the volatile fission product species would be in a condensed state. As particles they would be removed by the air cleaning system. 


\section{SUMMARY AND CONCLUSIONS}

A study was carried out to determine the fate of condensible contaminants carried by a hot gas stream into an aqueous scrubber. Contaminants of particular interest were $\mathrm{NaI}, \mathrm{SeO}_{2}$, and $\mathrm{Sb}_{2} \mathrm{O}_{3}$. These chemical species represent fission product forms which could enter the containment atmosphere under postulated core disruptive accident conditions. An aqueous scrubber system consisting of a quench chamber, a venturi scrubber, and a fibrous bed scrubber in series has been proposed to trap airborne contaminants from purged containment gases. Since hot gas is rapidiy cooled in the quench chamber, vapor forms of the three species would condense, and either form nuclei or deposit onto sodium oxide aerosol particles which would also be present.

The approach adopted in the present study was to develop a simple mathematical model of the cooling and condensation processes so that the size of the particles formed could be estimated. From the size of the particles formed, their capture efficiency in downstream air cleaning components was modeled on the basis of state-of-the-art knowledge.

It was recognized that some of the important variables might take a range of numerical values, and these were treated as parameters. The overall removal efficiency was computed to show how it varied with each parameter.

Specific conclusions and summary statements which are supported by the work completed are as follows.

1. If condensible fission product species are present in hot containment gases, they will undergo nucleation in the quench chamber.

2. While both homogeneous and heterogeneous (onto sodium aerosol particles) nucleation will occur, homogeneous nucleation will dominate. Thus a submicron aerosol of the condensing material will be formed in the quench chamber. 
3. Freshly formed aerosols will be small in size and large in number, and therefore will agglomerate rapidly. Most of the fine aerosol will co-agglomerate with sodium aerosol particles before the gas exits from the quench chamber.

4. The large easily-removed particles of sodium compounds will be efficiently washed out by the quench spray.

5. The eductor venturi, located downstream from the quench chamber, will not exhibit a high removal efficiency because the large particles will already have been removed by the quench spray.

6. Efficient removal of particles of all sizes will be achieved by the fibrous bed scrubber, assuring that both freshly condensed particles and sodium compound particles will be efficiently removed by the air cleaning system. For the base case, it was estimated that $99.97 \%$ of freshly condensed aerosol mass would be removed by the scrubbing system.

7. A minimum removal efficiency of $97 \%$ can be identified by reference to the penetration curve for the fibrous bed scrubber. This minimum efficiency, which can be experimentally verified using an aerosol having an aerodynamic mean particle diameter of 0.4 micrometers, provides a conservative lower limit efficiency for condensible contaminants.

8. If removal efficiencies significantly higher than this minimum value were required for condensible contaminants, then additional work would probably be required to verify the predictions made herein. 


\section{REFERENCES}

1. R. K. Hilliard, J. D. McCormack, and A. K. Postma, Evaluation of Air Cleaning System Concepts for Emergency Use in LMFBR Plants, HEDL-TME 76-41, Hanford Engineering Development Laboratory, Richland, Washington, December, 1976.

2. A. K. Postma, Laboratory Evaluation of De-Entrainors Made From Teflon and Polypropylene Fibers, BNWL-415, Batte1le Northwest Laboratory, Richland, Washington, 1967.

3. M. F. Kennedy, et a1., Primary Aerosol Particle-Size Distribution From Homogeneous Nucleation Condensation and Particle Growth, NUREG-0391, U. S. Nuclear Regulatory Commission, Washington, D. C., December, 1977.

4. N. H. Fletcher, The Physics of Rain Clouds, Cambridge University Press, London, 1962.

5. K. Yamamato, et al., Sodium Vapor Deposition Studies Related to the Development of Components for LMFBR in Japan, Paper No. 9, International Working Group on Fast Reactors, Technical Committee Meeting on Aerosol Formation, Vapor Deposits, and Sodium Vapor Trapping, Cadarache, France, December 13-17, 1976, Report CONF-761218, IWGFR-15.

6. J. F. Van de Vate, Aerosol Behavior in Spaces With a Heated Pool of Sodium on the Floor, Paper No. 12, International Working Group on Fast Reactors, Technical Committee Meeting on Aerosol Formation, Vapor Deposits, and Sodium Vapor Trapping, Cadarache, France, December 13-17, 1976, Report CONF-761218, IWGFR-15.

7. G. E. Cogin and G. E. Kimba11, The Vapor Pressure of Some Alkali Halides, J. Chem Phys, 16, pp 1035-1048, 1948.

8. J. G. Knudsen and D. L. Katz, Fluid Dynamics and Heat Transfer, p. 310, McGraw-Hill Book Co, New York, 1958.

9. N. A. Fuchs, The Mechanics of Aerosols, The Macmitlan Co., New York, 1964.

10. R. S. Hubner, et a1., HAA-3 User Report, AI-AEC-13038, Atomics Internationa 1, Canoga Park, California, August 1974.

11. W. E. Ranz, and J. B. Wong, Impaction of Dust and Smoke Particles on Surface and Body Collectors, Ind. Eng. Chem, 44, pp 1371-1381, 1952.

12. I. Langmuir, J. Meteor, 5, p. 175, 1948. 
13. A. K. Postma, R. L. Ritzman, J. A. Gieseke, and E. W. Schmidt, Models for Predicting the Removal of Airborne Contaminants by Reactor Containment Sprays, BNWL-B-417, Battelle Pacific Northwest Laboratory, Richland, Washington, June, 1975.

14. M. Suneja, as quoted in: M. Kerker and V. Hampl, Scavenging of Aerosol Particles by a Falling Water Drop and Calculation of Washout Coefficients, J. Atm. Science, 31, pp 1368-1376, July, 1974.

15. J. Pich in Aerosol Science, ed. by C. N. Davies, Academic Press, London, $196 \overline{6 .}$

16. C. N. Davies, Air Filtration, Academic Press, London, 1973.

17. J. H. Perry, ed., Chemical Engineers' Handbook, Third Edition, p. 538, McGraw-Hil1 Book Co., New York 1950.

18. D. P. Birmingham, et al., Hypothetical Core Disruptive Accident Considerations in CRBRP. Volume 2. Assessment of Thermal Margin Beyond the Design Base, WARD-D-0187, Westinghouse Electric Corporation Advanced Reactors Division, Madison, Pennsylvania, Apri1, 1978.

19. J. M. Atwood, Sodium Engineering and Technology Technical Progress Report Ju7y, August, September 1977, pp 79-89, HEDL-TME 77-38, Hanford Engineering Development Laboratory, Richland, Washington, December, 1977.

20. J. H. Perry, ed., Chemical Engineers' Handbook, Fourth Edition, p.3-19, McGraw-Hil1 Book Co., New York, 1963.

21. S. F. Bankert, et a1., Containment Margins in FFTF for Postulated Failure of In-Vessel Post-Accident Heat Removal, HEDL-TME 77-18, Hanford Engineering Development Laboratory, Richland, Washington, April, 1977.

22. R. G. Behrens and G. M. Rosenblatt, Vapor Pressure and Thermodynamics of Orthorhombic Antimony Trioxide, J. Chem Thermo, 5, pp 173-188, 1973.

23. R. G. Behrens, R. S. Lemons, and G. M. Rosenblatt, Vapor Pressure and Thermodynamics of Selenium Dioxide. The Enthalpy of Atomization of $\mathrm{SeO}_{2(\mathrm{~g})} \cdot$, J. Chem. Thermo, 6 , pp 457-466, 1974. 